NBSIR 85-3108

\begin{tabular}{l} 
A Preliminary Study of the \\
Vertical Stack to Horizontal Drain \\
Entry Condition As An Extension \\
to the Modeling of Unsteady \\
Partially Filled Pipe Flow \\
\hline
\end{tabular}

Dr. J.A. Swaffield, Reader

Mechanical Engineering Department

Building Technology

Brunel University

Uxbridge, England

Dr. Lawrence S. Galowin

U.S. DEPARTMENT OF COMMERCE National Bureau of Standards National Engineering Laboratory Center for Building Technology

Gaithersburg, MD 20899

December 1984

Issued February 1985

$Q C$

".S. DEPARTMENT OF COMMERCE

100

.456

$85-3108$ 



\section{A PRELIMINARY STUDY OF THE}

VERTICAL STACK TO HORIZONTAL DRAIN

ENTRY CONDITION AS AN EXTENSION

TO THE MODELING OF UNSTEADY

PARTIALLY FILLED PIPE FLOW

Dr. J.A. Swaffield, Reader

Mechanical Engineering Department.

Building Technology

Brunel University

Uxbridge, England

Dr. Lawrence S. Galowin

U.S. DEPARTMENT OF COMMERCE

National Bureau of Standards

National Engineering Laboratory

Center for Building Technology

Gaithersburg, MD 20899

December 1984

Issued February 1985

U.S. DEPARTMENT OF COMMERCE, Malcolm Baldrige, Secretary NATIONAL BUREAU OF STANDARDS. Emest Amblor, Diroctor 



\section{SUMMARY}

The finite difference based method of characteristics model for unsteady partially filled pipe flow was extended to include the model for the stack to horizontal drain entry boundary condition. The conditions at drain entry are defined in terms of the energy of the terminal annular flow velocity in the stack, together with an appropriate loss coefficient function at the entry. The hydraulic solutions link the branch drains, fittings, vertical soil stack, and building drain. The analysis permits any combination of drainage load patterns from simultaneous, overlapping, or sequence of discharge events. Preliminary simulations utilizing this model indicate that the modeling technique extends the existing horizontal network analysis program for determination of multistory building drainage systems. The sizing procedure provides the hydraulic capacity of drains for specified pipe sizes, pipe pitch, and wall roughness factors.

Keywords: Drain stack to horizontal drain flows; drain system design; plumbing drainage; unsteady flow in drains. 
A

C

D

E

$\mathrm{E}_{\mathrm{B}}$

e

f

g

h

$\mathrm{h}_{\mathrm{O}}$

$\mathrm{h}_{\mathrm{n}}$

$\mathrm{K}$

k

L

m

n

Q

$\mathrm{Q}_{\mathrm{S}}$

$\operatorname{Re}$

$\mathrm{S}$

$\mathrm{S}_{0}$

$\mathrm{T}$

$t$

V

$\mathrm{V}_{0}$

$v_{t}$

$\mathrm{z}_{\mathrm{O}}$

○

$\lambda$

v

()

$\tau_{\mathrm{O}} \mathrm{L}$

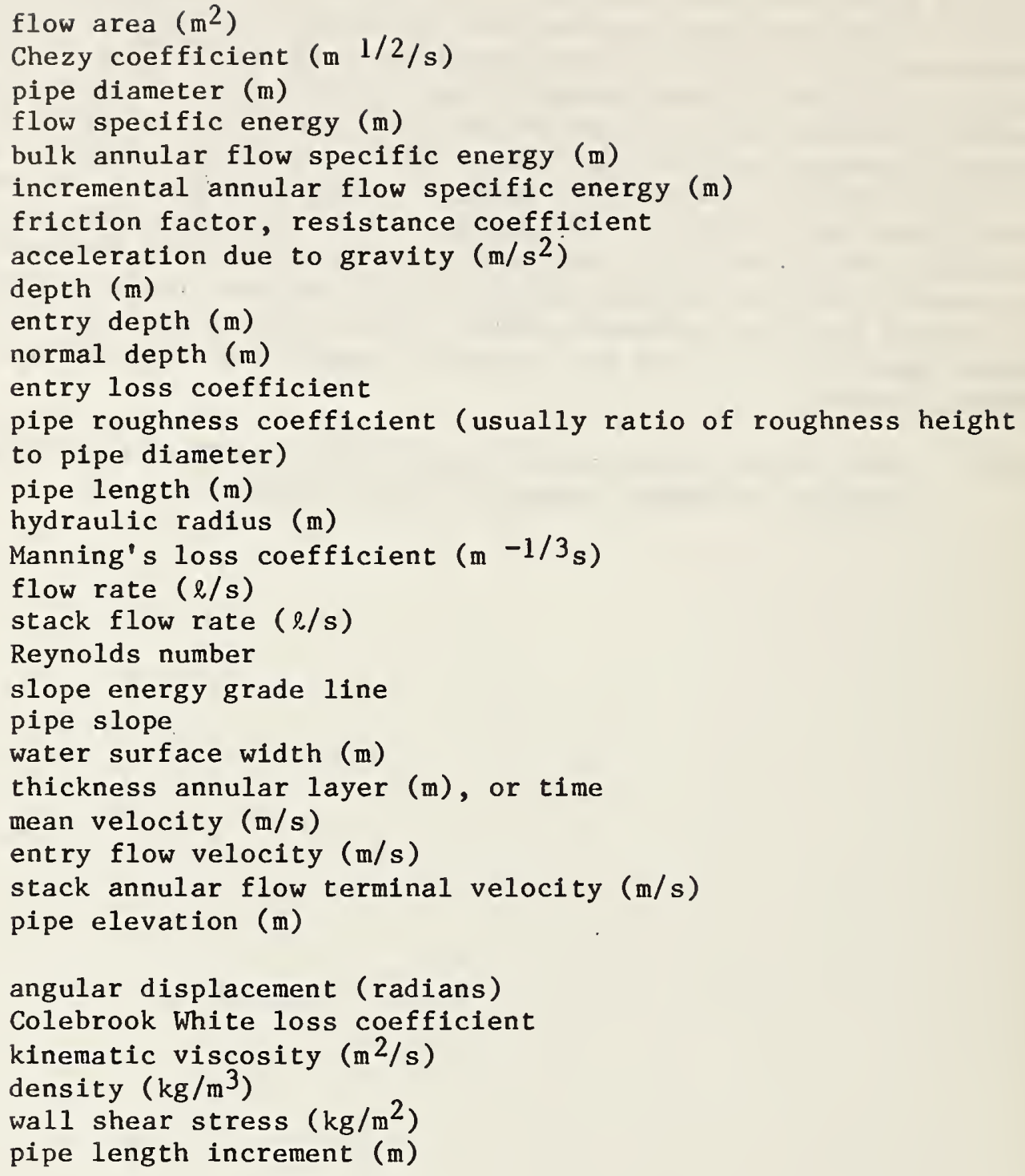




\section{SUMMARY}

The finite difference based method of characteristics model for unsteady partially filled pipe flow was extended to include the model for the stack to horizontal drain entry boundary condition. The conditions at drain entry are defined in terms of the energy of the terminal annular flow velocity in the stack, together with an appropriate loss coefficient function at the entry. The hydraulic solutions link the branch drains, fittings, vertical soil stack, and building drain. The analysis permits any combination of drainage load patterns from simultaneous, overlapping, or sequence of discharge events. Preliminary simulations utilizing this model indicate that the modeling technique extends the existing horizontal network analysis program for determination of multistory building drainage systems. The sizing procedure provides the hydraulic capacity of drains for specified pipe sizes, pipe pitch, and wall roughness factors.

Keywords: Drain stack to horizontal drain flows; drain system design; plumbing drainage; unsteady flow in drains. 


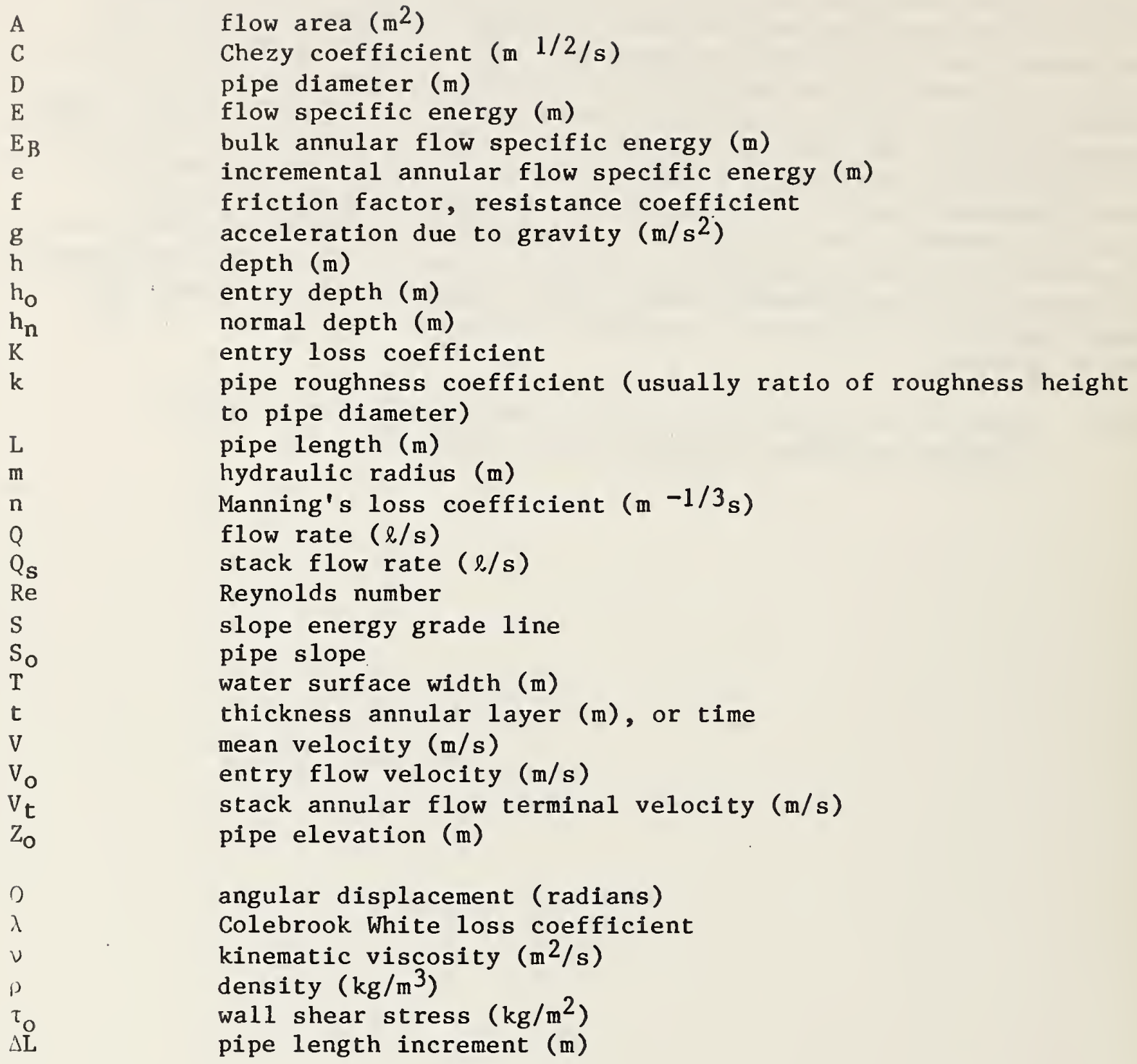


1. INTRODUCTION $\ldots \ldots \ldots \ldots \ldots \ldots \ldots \ldots \ldots \ldots \ldots \ldots \ldots \ldots \ldots \ldots \ldots \ldots \ldots \ldots \ldots \ldots \ldots \ldots \ldots$

2. DEVELOPMENT OF THE VERTICAL STACK TO HORIZONTAL DRAIN NUMERCIAL MODEL

2.1 Entry Energy Based on Fully Developed Vertical Stack Flow ..... 2

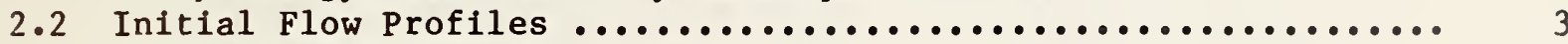

2.3 Initial Consideration of Loss Coefficient at Entry to Horizontal Drain ................................ 5

3. FLOW SIMULATION $\ldots \ldots \ldots \ldots \ldots \ldots \ldots \ldots \ldots \ldots \ldots \ldots \ldots \ldots \ldots \ldots \ldots \ldots \ldots \ldots \ldots \ldots . . \ldots . \ldots$

3.1 Initial Flow Depth Profiles Along the Horizontal Drain ........ 7

3.2 Simulation of Vertical Stack Annular Thickness and Terminal velocity ....................................... 9

3.3 Surge Attenuation Following Stack Discharge to a Horizontal

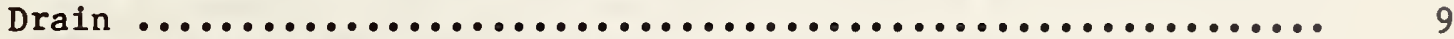

3.4 Effect of Baseflow on Surge Attenuation ................... 10

3.5 Comparison of Predicted and Observed Depth Profiles for a Horizontal Drain Supplied by a Stack .................... 10

4. CONCLUSIONS ........................................ 13

5. REFERENCES $\ldots \ldots \ldots \ldots \ldots \ldots \ldots \ldots \ldots \ldots \ldots \ldots \ldots \ldots \ldots \ldots \ldots \ldots \ldots \ldots \ldots \ldots \ldots \ldots \ldots \ldots . \ldots \ldots$ 


\section{LIST OF FIGURES}

Page

Figure 1. Summary of the methods of characteristics solution of the unsteady partially filled pipe flow equations .............

Figure 2. Application of the method of characteristics to unsteady supercritical partially filled pipe flow ............... 16

Figure 3. Fully developed annular flow in vertical stacks .......... 17

Figure 4. Flow rate vs: time inflow to a vertical stack translated into annular thickness and terminal energy vs. time profiles .....................................

Figure 5. Calculation of the energy grade line for gradually varied flow ......................................

Figure 6. Development of flow depth profiles in gradually varled pipe

Figure 7. Upstream boundary formed by an entry energy equation

Figure 8. Depth profiles for initial steady flow along drain at $1 / 50$

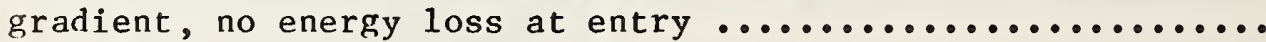

Figure 9. Depth profiles for initial steady flow along drain at a $1 / 100$

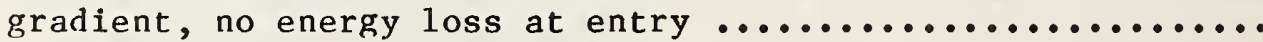

Figure 10. Influence of the entry energy loss coefficient on development on initial steady flow depth profiles $(1 / 100)$............

Figure 11. Influence of the entry energy loss coefficient on development on initial steady flow depth profiles $(1 / 50)$..............

Figure 12. Annular stack flow thickness as a function of stack steady flow rate ......................................

Figure 13. Stack annular flow terminal velocities compared to existing experimental data ...............................

Figure 14. Flow depth at pipe entry compared to annular stack flow thick-

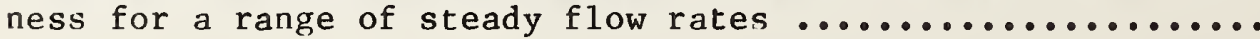

Figure 15. Peak depths predicted along the horizontal drain for a range of inflow profiles $(1 / 50)$

Figure 16. Peak depths predicted along the horizontal drain for a range of inflow profiles $(1 / 100)$ 
Figure 17. Peak flow rates predicted locally along the horizontal drain for a range of inflow profiles $(1 / 50)$................. 30

Figure 18. Peak flow rates predicted locally along the horizontal drain for a range of inflow profiles $(1 / 100)$

Figure 19. Jocation of predicted peak flow depth and local flow rate for a range of inflow profiles $(1 / 50) \ldots \ldots \ldots \ldots \ldots \ldots \ldots \ldots \ldots \ldots$

Figure 20. Location of predicted peak flow depth and local flow rate for a range of inflow profiles $(1 / 100) \ldots \ldots \ldots \ldots \ldots \ldots \ldots \ldots \ldots$

Figure 21. Peak flow depth and local flow rate envelopes along the length of the horizontal drain (1/50)

Figure 22. Peak flow depth and local flow rate envelopes along the length of the horizontal drain $(1 / 100)$

Figure 23. Depth vs. time profiles at a number of stations along the horizontal drain $(1 / 50)$

Figure 24. Depth vs. time profiles at a number of stations along the horizontal drain $(1 / 100)$

Figure 25. Summary of baseflow effect on the peak depth and local flow

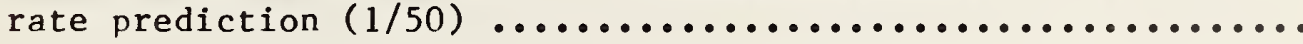

Figure 26. Summary of baseflow effect on the peak depth and local flow

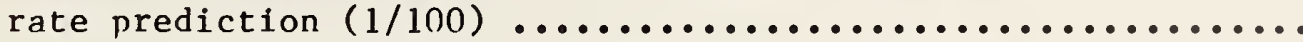

Figure 27. Comparison of observed and predicted surge attenuation downstream of a vertical stack to horizontal drain entry ........

Figure 28. Comparison of observed and predicted surge attenuation downsteam of a vertical stack to horizontal drain entry .........

Figure 29. Comparison of predicted surge depths downstream of a vertical stack to a horizontal drain entry for two entry energy loss

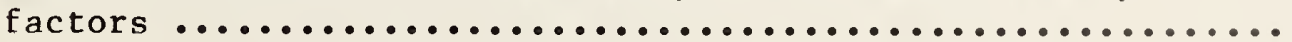

Figure 30. Comparison of predicted surge profile depths in a horizontal drain downstream of a vertical stack for composite loading profiles 
LIST OF TABLE

Page

Table 1. Normal depths in a $100 \mathrm{~mm}$ smooth partially filled pipe at $1 / 100$

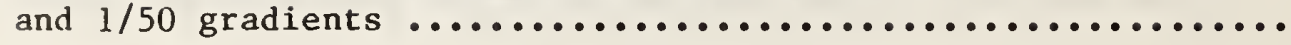
8 


\section{INTRODUCTION}

The unsteady flow equations defining partially filled pipe flow may be solved by means of the finite difference method of characteristics. Programs to utilize this technique have been developed and fully described in previous progress reports and published papers [1].

The development of the basic equations and their application in finite difference form to describe unsteady partially filled pipe flow are illustrated by figures 1 and 2 . In common with other finite difference applications the methods require a knowledge of both initial conditions and the system boundary equations to allow the solution to proceed. For a single pipe as shown in figure 2, under supercritical flow conditions, the exit boundary is supplied by the $\mathrm{C}^{+} \mathrm{C}^{-}$characteristics from the preceding upstream section. In addition to the boundary conditions the finite difference solution also requires knowledge of the initial flow depth and velocity along the pipe length at the start of the simulation. Normally a small steady flow is assumed along the whole pipe length prior to the introduction of the drain load profile.

The flow profiles entering the drain may be assumed for initial case studies. For example, a high energy steady inflow will become progressively deeper along the pipe's length as its energy is dissipated. The flow depth will eventually reach the normal steady uniform flow depth, however the distance required for this will depend on the entry energy, the flow rate and pipe parameters such as diameter, roughness, slope, etc. The entry condition at the head of the drain depends on the inflow conditions resulting from the flow upstream of the entry section. In this report the upstream flow conditions are derived to represent fully developed vertical stack flow entering the "horizontal" drain. slope etc. Determination of this initial flow depth profile as a function of time at the horizontal drain entry will be presented based upon gradually varied flow theory. 
2. DEVELOPMENT OF THE VERTICAL STACK TO HORIZONTAL DRAIN NUMERICAL MODEL

\subsection{ENTRY ENERGY BASED ON FULLY DEVELOPED VERTICAL STACK FLOW}

Figure 3 illustrates the annular nature of vertical stack flow under fully developed flow conditions [2].

For a section $\Delta \mathrm{L}$ of the stack a force balance equation for the falling water may be expressed under steady developed flow conditions, where stress at the air water interface is neglected, as

$$
\pi \mathrm{D} \tau_{\mathrm{o}}(\Delta \mathrm{L})=\rho \pi \mathrm{Dt}(\Delta \mathrm{L}) \mathrm{g}
$$

where $\mathrm{D}=$ pipe diameter

$t$ = annular thickness

$\tau_{0}=$ wall shear stress resisting motion

It follows that:

$$
\tau_{0}=p \quad g
$$

Following the work of Colebrook White it may be shown that the shear stress may be expressed, for full bore pipe flow by the equation

$$
\sqrt{\frac{\rho V^{2}}{8 \tau_{0}}}=-2 \log _{10}\left[\frac{k}{3.7 \mathrm{D}}+\frac{2.51}{\operatorname{Re}} \sqrt{\frac{\rho V^{2}}{8 \tau_{0}}}\right]
$$

where $\quad V$ is flow mean velocity

$k$ is surface roughness coefficient

and $\quad$ Re is Reynolds Number, based on pipe diameter.

Ackers (3) has shown that equation (3) may be applied to partially filled pipe flow if the characteristic length $D$ is replaced by the hydraulic radius:

$$
\mathrm{m}=\frac{\text { Area }}{\text { Wetted Perimeter }}
$$

which for a full bore pipe flow is

$$
\mathrm{m}=\mathrm{D} / 4
$$

Replacing Re by $\mathrm{VD} / \nu$ and substituting for $\mathrm{D}$ in terms of $\mathrm{m}$ ylelds

$$
\sqrt{\frac{\rho V^{2}}{8 \tau_{0}}}=-2 \log _{10}\left[\frac{\mathrm{k}}{14.8 \mathrm{~m}}+\frac{2.51 v}{4 V \mathrm{~V}} \sqrt{\frac{\rho V^{2}}{8 \tau_{0}}}\right]
$$

For the annular flow condition in the vertical stack, it has been shown that

$$
\tau_{0}=\rho t g
$$


and, it also follows that

$$
m=\frac{\pi D t}{\pi D}=t
$$

if $t \ll D$, as is the case here $[2,4]$

Substituting from (2) and (6) into (5) yields an expression for annular thickness, $t$, where the volumetric flow $Q$ is taken as

$$
Q=\pi D t V
$$

where $\mathrm{V}$ is the mean annular velocity

$$
\left(\frac{Q}{4 \pi D t}\right) \sqrt{\frac{1}{2 g t}}=-\log _{10}\left[\frac{k}{14.8 t}+\frac{0.3140 v}{t} \sqrt{\frac{1}{2 g t}}\right]
$$

This expression may be solved to yield $t$ for a given $Q$ and hence the annular velocity $\mathrm{V}$.

The specific kinetic energy in the annular downflow then becomes

$$
E=\frac{1}{2} \frac{V^{2}}{g}
$$

Naturally, the expressions above only apply strictly to fully developed flow. Previous work [4] has shown that the necessary vertical stack length to reach this condition is less than $3 \mathrm{~m}$ in many design cases, $1 . e$. , less than a story height. In those cases the derivation above may therefore be utilized. The influence of vertical stack pipe wall roughness for given flow rate Q, upon $\tau_{0}$ follows from (8) and (2).

The flow rate in the stack may vary with time due to the imposed load from the branch drain, as sketched, figure 4. However, it may be assumed that the flow rate profile is made up of an infinite number of fully developed flow sections, thus allowing the annular thickness and energy vs. time profiles to be developed as shown. There profiles may then be taken as the entry energy profiles at the drain upstream boundary. With sufficient height of fall in the vertical stack the equilibrium terminal velocity, $V_{t}$, is attained.

\subsection{INITIAL FLOW PROFILES}

The development of flow depth along the length of the horizontal drain pipe under the initial steady flow conditions may be generated by reference to gradually varied flow theory. The basic assumption is that the local head at any section is given by the equivalent steady flow loss equation, either Manning's or Darcy's equation, utilizing the Colebrook White friction factor expression.

Depth profile predictions by numerical integration are based on this assumption, expressed in figure 5 by 


$$
\frac{d}{d L}\left[\frac{v^{2}}{2 g}+\left(z_{o}-s_{o} L\right)+h\right]=-s
$$

where $S$ is the slope of the energy grade line determined from Mannings equation or from the general Chezy expression:

$$
\begin{aligned}
\sqrt{S}=\frac{n Q}{A m^{2 / 3}} & \text { (Manning, metric) } \\
S=\frac{V^{2}}{c^{2} m} & (\text { Chezy) }
\end{aligned}
$$

Hence $-\frac{\mathrm{V}}{\mathrm{g}} \frac{\mathrm{dV}}{\mathrm{dL}}+\mathrm{S}_{\mathrm{o}}-\frac{\mathrm{dh}}{\mathrm{dL}}=\mathrm{S}$

Then, from, $\mathrm{Q}=\mathrm{VA}$

$$
\frac{d V}{d L} A+V \frac{d A}{D L}=0
$$

Also, as $\mathrm{dA}=\mathrm{Tdh}$, where $\mathrm{T}$ is the water surface width (which does not change with L, or changes slowly) it follows that

$$
\frac{\mathrm{dV}}{\mathrm{dL}}=-\frac{\mathrm{V}}{\mathrm{A}} \frac{\mathrm{dA}}{\mathrm{dL}}=-\frac{\mathrm{VT}}{\mathrm{A}} \frac{\mathrm{dh}}{\mathrm{dL}}=-\frac{\mathrm{QT}}{\mathrm{A}^{2}} \frac{\mathrm{dh}}{\mathrm{dL}}
$$

and substituting yields

$$
\begin{aligned}
& \left(\frac{\mathrm{Q}^{2} \mathrm{~T}}{\mathrm{gA}^{3}}\right) \frac{\mathrm{dh}}{\mathrm{dL}}+\mathrm{S}_{\mathrm{o}}-\frac{\mathrm{dh}}{\mathrm{dL}}=\mathrm{S} \\
& \mathrm{dL}=-\left[\left(1-\frac{\mathrm{Q}^{2} \mathrm{~T}}{\mathrm{gA}^{3}}\right) /\left(\mathrm{S}-\mathrm{S}_{\mathrm{o}}\right)\right] \mathrm{dh}
\end{aligned}
$$

or the distance along the flow profile, between two depths $h_{0}$ and $h_{1}$, becomes

$$
L=\int_{h_{0}}^{h_{1}}\left[\frac{1-Q^{2} T / g A}{\left(S_{O}-S\right)}\right] d h
$$

Figure 6 illustrates this integration.

In order to numerically evaluate (12) it is necessary to define a boundary depth at the pipe entry.

The available flow energy at the horizontal drain entry, assuming no losses, is based on the vertical stack annular specific flow energy,

$$
E=h_{0}+\frac{v_{0}^{2}}{2 g}
$$


where $h_{0}$ and $v_{0}$ are the flow depth and velocity at entry to the horizontal drain.

Substituting $E=\frac{1}{2} \frac{V_{t}^{2}}{g}, y i e l d s$

$$
\frac{1}{2} \frac{V_{t}^{2}}{g}=h_{0}+\frac{V_{o}^{2}}{2 g}=h_{0}+\left(\frac{Q_{0}}{A o}\right)^{2} \frac{1}{2 g}=F\left(h_{0}\right)
$$

and solving for $h_{0}$, with $V_{0}=Q_{0} / A_{0}$ and $A_{0}=f\left(h_{0}\right)$ yields the upstream boundary depth.

The downstream boundary may be taken as the flow normal depth, $h_{n}$ at the distance downstream to be determined from the integration of (12). As the flow is supercritical, the depth may rise gradually to this value with no discontinuity, such as a hydraulic jump.

The choice of $\mathrm{dh}$ values in the numerical integration is based on the difference between the control depth, $h_{0}$ and the downstream "target" depth, $h_{n}$. A reasonable integration step size is given by

$$
d h=\left(h_{n}-h_{0}\right) / 30
$$

Once the depth reaches $h_{n}$ the remaining downstream profile is assumed to be at that constant depth.

For short pipe lengths, or high energy steady initial flows, it may be that the normal depth is not achieved within the available pipe length. For this case the integration is terminated when $\Sigma \Delta L$ exceeds the pipe length, $1 . e ., \Sigma \Delta L>L$. A valid flow profile is however achieved in this case.

\subsection{INITIAL CONSIDERATION OF LOSS COEFFICIENT AT ENTRY TO HORIZONTAL DRAIN}

Figure 7 illustrates the conditions for an initial derivation of the energy loss at the entry elbow bend to the horizontal drain. It is assumed that within the annular flow the specific energy, e, along "streamlines" of the downflow is represented by the kinetic energy at the terminal velocity condition. Degradation of the energy is assumed to result from mixing at the bend due to the varying orientation of flow directions from the vertical to horizontal. The equation may be assumed as:

$$
e=\frac{v_{t}^{2}}{2 g}\left(\sin ^{2} \frac{1}{2} \theta\right)
$$

where $V_{t}$ is the mean annular (terminal) velocity. The equation (14) Indicates the vertically falling flow at $\theta=0$ loses its entire energy content and only adds mass at the drain inlet and at $\theta=\pi$ the streamline total energy content $1 \mathrm{~s}$ 
preserved. Then a relation for the specific energy content of the annular mass flow* may be obtained as:

$$
\int_{0}^{2 \pi} e\left(\frac{D}{2}-t\right) t d \theta=E_{B} \frac{\pi}{4}\left[D^{2}-(D-2 t)^{2}\right]
$$

Where $E_{B}$ is the annular energy. Substituting for e yields

$$
\begin{aligned}
E_{B} \frac{\pi}{4} & {\left[D^{2}-(D-2 t)^{2}\right]=2 \int_{0}^{\pi}\left(\frac{D}{2}-t\right) t \frac{v_{t}^{2}}{2 g}\left(\sin ^{2} \frac{\theta}{2}\right) d \theta } \\
& =\left(\frac{D}{2}-t\right) \frac{t}{g} v_{t}^{2} \int_{0}^{\pi}\left(\sin ^{2} \frac{\theta}{2}\right) d \theta \\
& =\left(\frac{D}{2}-t\right) \frac{t}{g} v_{:}^{2}(\pi / 2) \\
E_{B} & =\frac{(D / 2-t)}{(D-t)} \frac{v_{t}^{2}}{2 g}
\end{aligned}
$$

For $t \ll D, E_{B} \rightarrow \frac{1}{2} \frac{V_{t}^{2}}{2 g}$

The model does not apply for $t \rightarrow D / 2$ (full bore pipe flow) since the turning losses at an elbow for full bore flow do not have comparable mixing. Flow separation from full bore downflow into a partially filled horizontal drain requires different physical modeling.

* The term (D/2-t) includes other losses for annual flow not in contact with the pipe wall. The use of $(D-t) 1 / 2$ (in average cross section area formulation for equation (15)) leads to a constant energy loss of 50 percent. 
Values of the factor modifying the kinetic energy term, $v_{t}^{2 / 2 g}$, are indicated below:

\begin{tabular}{|c|c|c|}
\hline $\begin{array}{l}\text { Pipe Diameter } \\
(\mathrm{mm})\end{array}$ & $\begin{array}{l}\text { Annular Film } \\
\text { Thickness } \\
\text { (mm) }\end{array}$ & $\begin{array}{c}\text { Ratio } \\
\text { Factor } \\
(D / 2-t) /(D-t)\end{array}$ \\
\hline 100 & $\begin{array}{r}25 . \\
12.5 \\
2.5\end{array}$ & $\begin{array}{l}.33 \\
.43 \\
.49\end{array}$ \\
\hline
\end{tabular}

Measured values from experiments for the annular thicknesses are difficult to obtain [2, 4]; however, indicated ranges are much less than 20 percent of the diameter and are a function of flow rate in the pipe, the pipe diameter, and wall roughness. For $D>t,(D / 2-t) /(D-t) \rightarrow 0.5$ hence an energy "loss" term of 50 percent may be a reasonable assumption for preliminary studies. Conditions other than for terminal velocity should retain the relationship (16) with $V_{t}$ replaced by the falling velocity as a function of length along the stack.

A study of entry loss effects could naturally include $\mathrm{K}$ values greater than unity. That condition would imply that the entry flow energy was higher than that appropriate to gravity driven stack flow as might be the case if the drain were supplied from a pressurized source. Surge flows generated in tests reported in [5] appear to correspond to pumped head conditions; there, other elbow losses may also be significant and required for inclusion of the analysis of the experimental results.

\section{FLOW SIMULATION}

\subsection{INITIAL FLOW DEPTH PROFILES ALONG THE HORIZONTAL DRAIN}

Figures 8 and 9 illustrates the depth profiles along a drain set at slopes of 0.02 and 0.01 and the other identified parameters for a range of initial flow rates. The profiles attain the normal depth at some distance along the pipe, thereafter the flow is assumed to continue at that depth until discharge at the pipe exit. The pipe length necessary to attain the steady normal flow depth increases for larger values of the steady flows rates, or as the pipe slope is increased.

Figures 10 and 11 illustrate the changes in profile for the $8 \mathrm{l} / \mathrm{s}$ case in pipes pitched at $1 / 100$ and $1 / 50$ for both a decreasing and increasing inlet energy factors. The reduction in entry energy indicated by the introduction of a loss coefficient will steepen the depth profile resulting in normal depths being achieved earlier in the pipe. The determination of the correct flow depth profile for the start of experiments or predictive simulation studies is important since it effectively provides the flow depth condition immediately ahead of the time-dependent surge wave.

It will be seen that if the inlet energy is artificially increased (e.g. pumped inlet condition [5] then the normal flow depth development is delayed. The corollary to this is that a fixed length pipe may be seen to carry rather more 
flow than suggested by the steady flow calculations of normal depth. For example, with $\mathrm{K}>1.0$ with pipe lengths less than $16 \mathrm{~m}$, the depths are less than those which occur with gravity drain conditions, from which it would be implied that higher flow rates can exist in the pipe without violating permissible half-filled depths. Care should be taken in any experimental work in this area to ensure that the entry energy is appropriate. Failure to do this could suggest enhanced carrying capacities that will not be found in practice. The presence of pipe fittings, such as a junction will result in substantial energy dissipation and the flow will therefore rapidly increase in depth, could fill the pipe cross section and be improperly interpreted as the hydraulic jump.

Table 1 presents normal depth values for $100 \mathrm{~mm}$ diameter pipes at gradients of $1 / 100$ and $1 / 50$.

Table 1. Normal Depths in a $100 \mathrm{~mm}$ Diameter Smooth Drain, $k=0.0$, Calculated via the Colebrook White Friction Loss Expression

\begin{tabular}{|c|c|c|}
\hline Pipe Gradient & $\begin{array}{c}\text { Flow Rate } \\
\ell / \mathrm{s}\end{array}$ & $\begin{array}{c}\text { Normal Depth } \\
\mathrm{mm}\end{array}$ \\
\hline \multicolumn{3}{|l|}{$1 / 100$} \\
\hline & 1.0 & 23.6 \\
\hline & 2.0 & 33.6 \\
\hline & 3.0 & 41.8 \\
\hline & 4.0 & 49.2 \\
\hline & 5.0 & 56.2 \\
\hline & 6.0 & 63.2 \\
\hline & 7.0 & 70.8 \\
\hline & 8.0 & 79.4 \\
\hline \multirow[t]{13}{*}{$1 / 50$} & 1.0 & 19.5 \\
\hline & 2.0 & 27.5 \\
\hline & 3.0 & 33.9 \\
\hline & 4.0 & 39.5 \\
\hline & 5.0 & 44.8 \\
\hline & 6.0 & 49.7 \\
\hline & 7.0 & 54.5 \\
\hline & 8.0 & 59.3 \\
\hline & 9.0 & 64.1 \\
\hline & 10.0 & 69.2 \\
\hline & 11.0 & 74.7 \\
\hline & 12.0 & 81.1 \\
\hline & 13.0 & 91.7 \\
\hline
\end{tabular}




\subsection{SIMULATION OF VERTICAL STACK ANNULAR THICKNESS AND TERMINAL VELOCITY}

Equation 8 may be utilized to calculate the annular flow thickness in the vertical stack for a range of steady flow rates. The terminal velocity corresponding to this thickness and flow rate may then be calculated from equation 7 .

Figures 12 and 13 illustrates the variation in terminal velocity and annular thickness with flow rate and also include previous experimental work reported elsewhere by Wise and Wyly $[2,4]$. The experimental values of terminal velocity probably exceed those predicted due to the difficutly in measuring the thickness of the annular layer (the air core interface with the water edge is at the same velocity due to the shear interaction) and as some of the flow will be "lost" as spray falling down the center of the pipe. Thus the value of terminal velocity calculated from equation 7 will be excessive as $t$ is underestimated. Wise's results also indicate this tendency.

With no energy loss in the êtntry bend the entry pipe flow at velocity is close to the stack terminal velocity. The results presented in figures 13 and 14 conform to the energy boundary equation (13a).

\subsection{SURGE ATTENUATION FOLLOWING STACK DISCHARGE TO A HORIZONTAL DRAIN}

The necessary equations to simulate wave attenuation along the length of the pipe have been developed [6]. The transition from the stack to the horizontal drain may be characterized by the entry energy boundary condition described previously, based on the annular terminal flow in the stack. Initial conditions along the horizontal drain may be set up utilizing the gradually varied flow theory outlined.

The wave formation in the horizontal drain may be viewed as being made up of two separate but superimposed mechanisms. As the surge progresses down the drain its depth increases as energy is dissipated. At the same time the wave attenuates due to the diffusion so that the superposition of these two effects results in a peak flow depth downstream of the entry along the pipe length. Figures 15 and 16 indicate the peak flow depths predicted for a range of inflow profiles. Figures 17 and 18 present the calculated peak flow rates, calculated at each pipe section as the product of $(\mathrm{V} \times \mathrm{A})$. It will be seen that the peak flow rates exceed the maximum inflow rates. This apparent anomaly is explained as the rising inflow surge generates waves moving with increasing wave speed greater than the mean velocity. The waves "overtake" the preceding flow and hence generate both depths and flow rates in excess of those predicted by a steady flow analysis.

It will also be seen that any surge alleviation provided by the reduction in surge flow is only manifested for the triangular inflow profiles. Profiles displaying a plateau at peak inflow rate tend to produce nearly similar maximum depths. This would suggest that the increased flow capacity often referred to as a result of attenuating surge flows is applicable only to relatively "sharp", triangular inflow rate vs. time profiles. 
Figures 19 and 20 indicate the location of the peak flow and peak depth along the horizontal drain for a range of inflow profiles (the calculation nodes are approximately $0.5 \mathrm{~m}$ apart). It will be noted that the peak flow rate invariably preceeds the location of peak depth. The same effect is also noticeable in figures 21 and 22 that indicate the peak depth and flow rate "envelopes" along the horizontal drain at gradients of $1 / 50$ and $1 / 100$. Figures 23 and 24 illustrate the flow depths at three stations along the drain over the duration of the simulation.

\subsection{EFFECT OF BASEFLOW ON SURGE ATTENUATION}

Figures 25 and 26 present peak flow depths and rates, together with their location for two computational test cases, for baseflows $0.2 \mathrm{l} / \mathrm{s}$ and $2 \mathrm{l} / \mathrm{s}$ with triangular flow profiles rising to $12 \mathrm{l} / \mathrm{s}$.

It would appear from these results that the baseflow only becomes an important parameter when the inflow surge time is sufficiently long so that the beneficial attenuation of the peak does not occur. Reference to the earlier figures 15 and 16 indicate that only the 2 second base triangle surge suffered any appreciable attenuation below the steady flow normal depth associated with its peak.

It is apparent that further data is required to be more specific as regards the effects of baseflow.

\subsection{COMPARISON OF PREDICTED AND OBSERVED DEPTH PROFILES FOR A HORIZONTAL DRAIN} SUPPLIED BY A VERTICAL STACK

Figures 27 and 28 present comparisons between experimentally measured depth vs. time profiles in a $75 \mathrm{~mm}$ pipe set at a gradient of 0.06 . Surges enter the pipe via a vertical stack supplied by a constant baseflow plus discharges from water closets at higher levels. The results presented were recorded in a dynamics of plumbing system test program $[7,8]$.

Unfortunately no data is available on the soil stack or drain inflow entry flow rate profile which is governed by the mixing at the horizontal drain branch elbows into the soil stack downflow. The flow rate profiles presented in figures 27 and 28, for the two baseflow cases, were best estimates of the likely water closet discharge profiles determined from the measured depth vs. time records in the horizontal branch drains at the second and third (story) level leading to the vertical stack. A single water closet on the third level and two back-to-back water closets on the second level were simultaneously discharged into constant downflows in the vertical stack.

The estimated discharge profiles were summed (as shown in the figures) and used to establish the inlet conditions to the drain model based upon the terminal velocity kinetic energy equation. Comparison between observed and predicted depth variation at a downstream depth tapping are shown. The time scale of the observed results have been adjusted so that the observed and predicted profiles move from the steady base flow condition at the same time. 
This approximate adjustment may account for some of the time scale deviations shown. The predicted normal depths with the steady baseflow (after the surge) are within 2 percent of measured values.

The results presented in figures 27 and 28 support the proposed model for stack to horizontal drain entry model. The baseflow does not affect the predicted peaks appreciably; however that was expected from the results shown in figures 25 and 26. Any improvement on the agreement requires an improved knowledge of the inflow flow rate profile, or at least a better estimate of the water closet flow rate discharge curves as modified by the junction fittings at the upper levels from the horizontal branch drains. Further research is necessary to fully account for mixing at entry fittings into the soil stack downflow. There have been no measurements of the distribution of annular flow properties in the vertical soil stack which are required to provide understanding of such gravity driven flow regimes. Investigations of annular flow phenomena indicate that surface waves are observed on vertical falling films. That suggests that superposition of surges on steady soil stack flows may take place, wave velocities greater than the mean falling flow velocities can occur, and flow redistribution may result, in addition to mass mixing at junctions or fittings.

For the same surge profile conditions of figure 27 , the predicted effects of the entry loss factor for $\mathrm{K}=0.5$ and 1.0 are shown in figure 29 at three stations along the length of the drain. The higher inlet energy condition $(\mathrm{K}=1.0)$ result in smaller peak depths compared with the lower inlet energy condition $(K=0.5)$. A steepened surge wave develops with higher energy content, due to the higher wave velocity $(\sqrt{ } \mathrm{gA} / \mathrm{T})$ overtaking the upstream flow which reinforces the surge surge wave front. Also it is noted that the surge depth attenuation for the higher energy case has not yet occurred up to the $10 \mathrm{~m}$ station. At that station the $\ell / D$ ratio (length of pipe to pipe diameter) is about 130; the prediction of large values of $\ell / D$ were reported in earlier experiments, reported in [5] with pumped inlet conditions. The sharp falloff from peak depth for the high energy computations at the $10.0 \mathrm{~m}$ station indicates that higher wave velocities have overtaken the surge. Those comparisons indicate that a need exists to improve the simplified drain inlet energy profile derivation. Observations made in experiments [6,7] suggest that a transition entry length in the horizontal drain, downstream of the elbow, may be required to account for a flow mixing transition in the modeling. 
In figure 30 , the results for the drain depths for three inlet profiles are shown. The inlet profiles considered are indicated below.

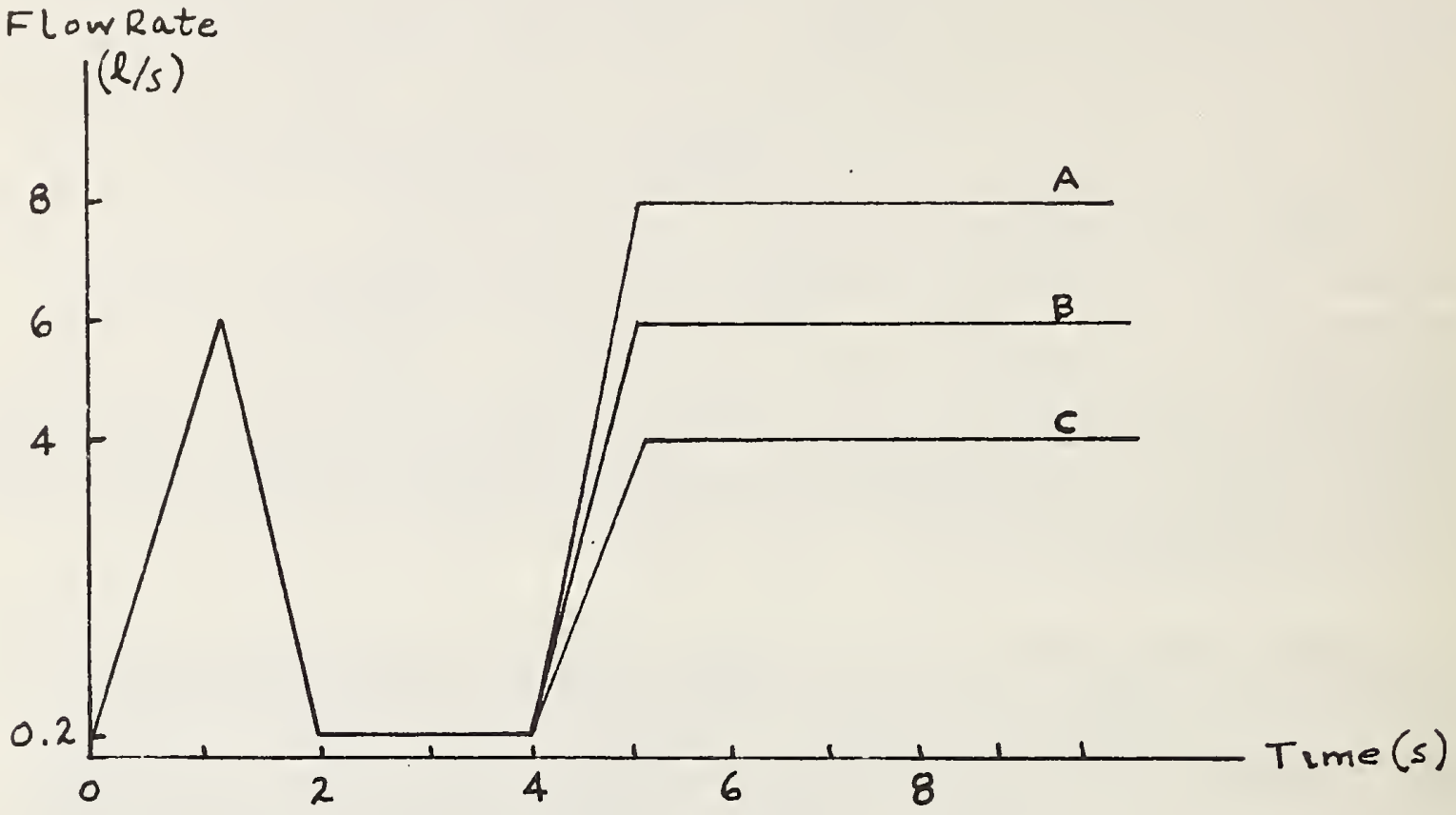

The assumed conditions represent waste discharge loading patterns due to a short time interval surge followed, after an interval, by a rise to a steady discharge flow. In all cases, the initial surge rapidly attenuates (as has been noted for figures 15 and 16). With increasing times the transient depths occur greater than the steady-state conditions before trending towards the normal depths (compare with values of table 1). For case A, the peak depths are 90 percent of full bore flow, whereas the normal depth was shown to be about 80 percent of full bore. Currently accepted plumbing code criteria for allowable partially filled drain pipe depths permit only half-filled pipes (although the report [9] on which the codes are based, assumed 75 percent for surge flows). Neither the transient measurement methods or calculation methods were available to the investigators or code writing panels at that time, consequently the effects discussed herein were only available by observations and greatly simplified measurement methods. Here, the larger wave speeds at the greater rate of increase to the higher steady flow rates cause a steepening of the wave and occurrence at somewhat earlier times for the same station. The peak depths occur at pipe length to diameter ( $l / D)$ ratios of about 100 for case $A$, and 75 for cases $B$ and $C$. The predicted results are consistent with the data from the pumped experiments [5] that showed the limit of hydraulic drain capacity, based upon a prescribed depth for a fixed length, is limited by lowest steady flow rate surge component and similar ranges of $(\ell / D)$ values. 


\section{CONCLUSIONS}

This report has introduced the concept of an energy entry condition to simulate vertical stack flow entering a horizontal drain. In general the model has been satisfactory in that no numerical instability problems have been encountered. The predictions of flow depth and flow rate through the stack and drain match the physical mechanisms known to occur for these flow situations. The predictive model provides for the first time, a comprehensive theoretical basis for explanation of the earlier experiments at NBS to establish the hydraulic capacity of drains.

It may be concluded that the simplified annular stack flow and entry energy model provides the first theoretical basis as a sultable method of linking networks of a number of horizontal drains with vertical stack discharging to a lower level pipe. Network horizontal pipe junctions solutions have progressed, in a parallel study [10], so that complex interconnected drainage system analysis is feasible now through combination of the predictive models. The models will be developed further and validated during the remainder of the projected program. 


\section{REFERENCES}

1. Swaffield, J.A. and Bridge, S., Quarterly Progress Reports to NBS under Contact No. DA 2004 .

2. Wise, AFE, "Drainage Services in Buildings," BRE Paper CP 35/73.

3. Ackers, P., "Resistance of Fluids Flowing in Channels and Pipes," HRP No. 1, HMSO 1958.

4. Wy 1 , R.S. and Eaton, H.N., "Capacities of Stacks in Sanitary Drainage Systems for Buildings," NBS Monograph 31, 1961.

5. Wyly, R. S., Investigation of the Hydraulics of Horizontal Drains in Plumbing Systems, NBS Monograph 1, 86, 1964.

6. Swaffield, J. A., "Application of Method of Characteristics to Model the Transport of Discrete Solids in Partially-Filled Pipe Flow NBS BSS 139, February 1982.

7. Galowin, L. S., Dynamics of Drain-Waste-Vent Plumbing Systems - A Preliminary Study, CIB W62 Water Supply and Drainage Seminar, Zurich, Switzerland, 1982 .

8. Galowin, L. S., Dynamics of Plumbing System Drainage and Vents, CIB W62 Water Supply and Drainage Seminar, Tel Aviv, Israe1, 1983.

9. Hunter, R. B., Methods of Estimating Loads in Plumbing Systems, NBS Building Materials and Structures Report, BMS 65, 1940.

10. Swaffield, J. A., Bridge, S., Galowin, L. S., "Development of Junction Model Suitable for Inclusion in an Unsteady Partially Filled Pipe Flow Network Analysis, CIB W62 Water Supply and Drainage Seminar, Tel Aviv, Israel, 1983. 
Energy grade line, slope $S=\tau_{0} / \rho g m$

Note: wave speed

$$
c=\sqrt{g^{A} / T}
$$

$$
\begin{aligned}
& S_{0}=\sin \alpha . \\
& m=A / P
\end{aligned}
$$

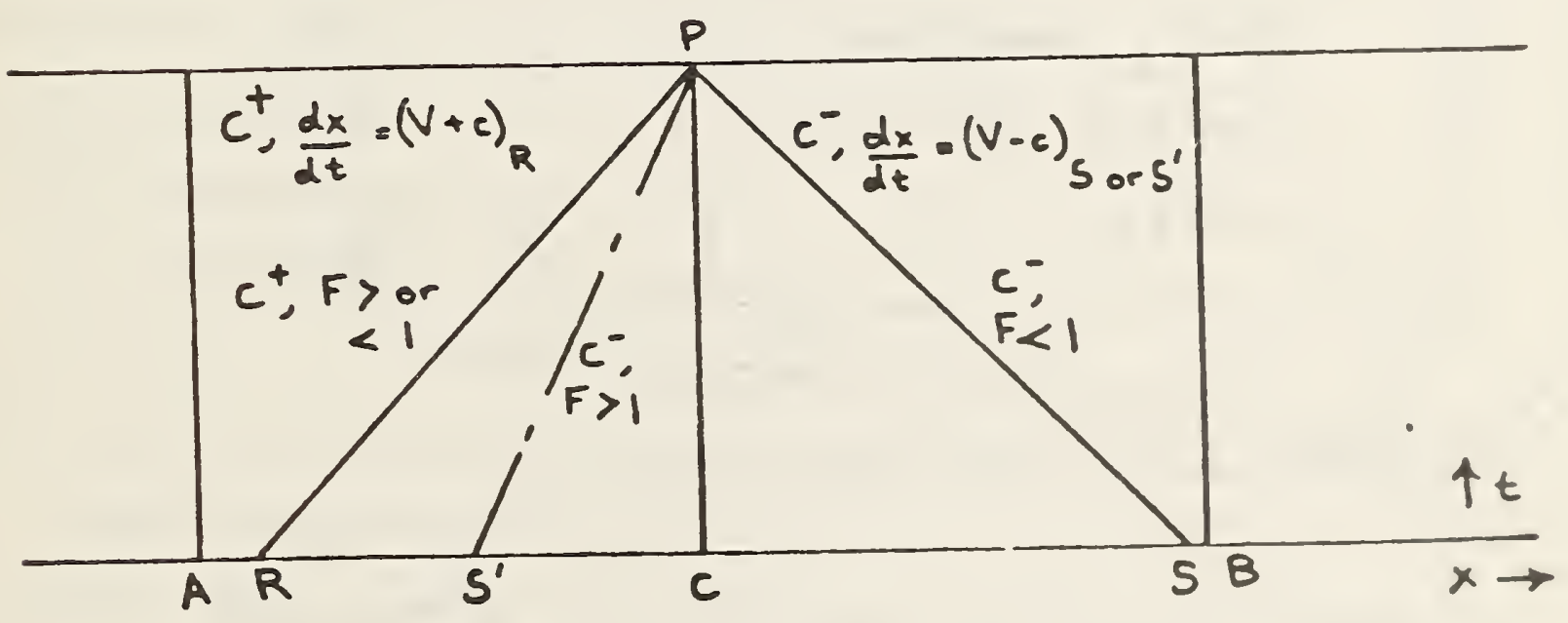

$F=$ Froude $N^{0},<1$ subcritical flow. $>1$ supercritical flow.

Note: if $\frac{d x}{d t}=V \pm c$

then $\frac{d V}{d t} \pm g \frac{d h}{d t}+g\left(S-S_{0}\right)=0$

Figure 1. Summary of method of characteristics solution of the unsteady partially filled pipe flow equations

15 


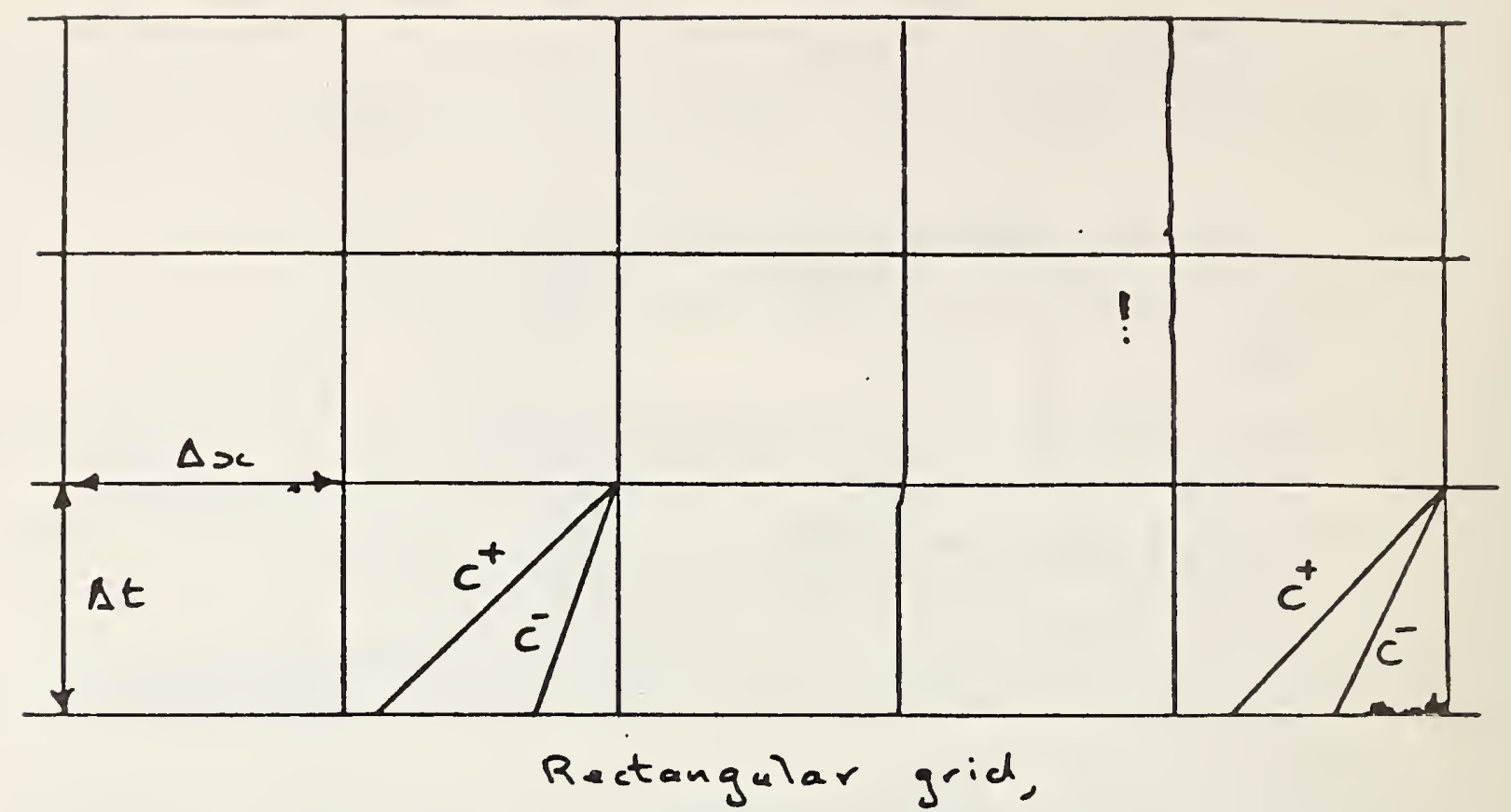
$\Delta t, \Delta x$ arranged so $C^{+}, C^{-}$ lines fall within grid as shown.

Entry condition provided by inflow energy
Flow at intermediate locations calculated by solution $\mathrm{C}^{+} \mathrm{C}^{-}$ equations

In supercritical flow, exit conditions based on upstream flow only, ie solution $C^{+}, C^{-}$equations

Figure 2. Application of the method of characteristics to unsteady supercritical partially filled pipeflow

16 


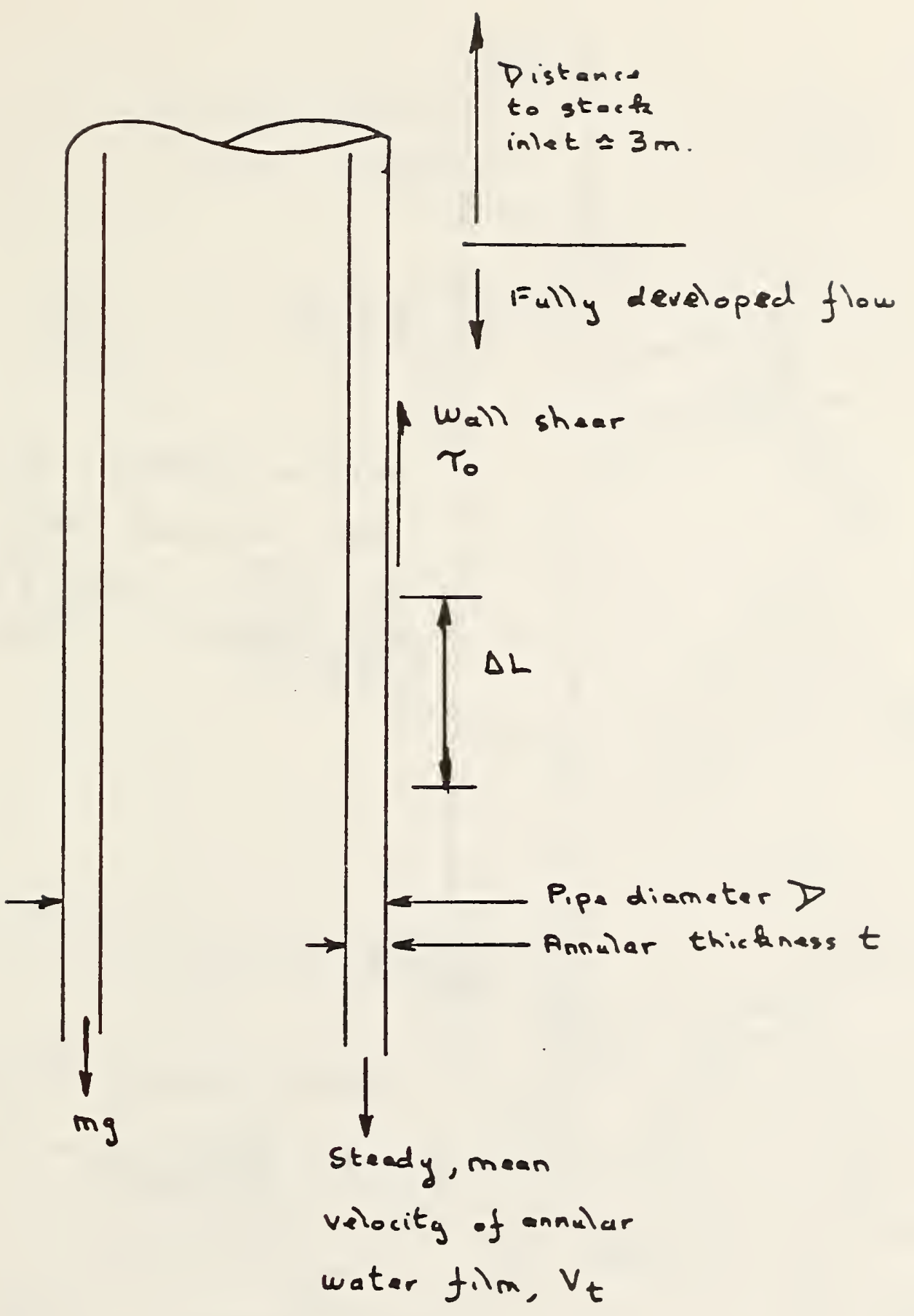

Balance of forces over $\Delta L$ in developed flow regime $y$ ils

$$
\begin{gathered}
\pi>\tau_{0} \Delta L=g \rho \pi D t \Delta L \\
\tau_{0}=\rho g t
\end{gathered}
$$

Figure 3. Fully developed annular flow in vertical stacks

17 


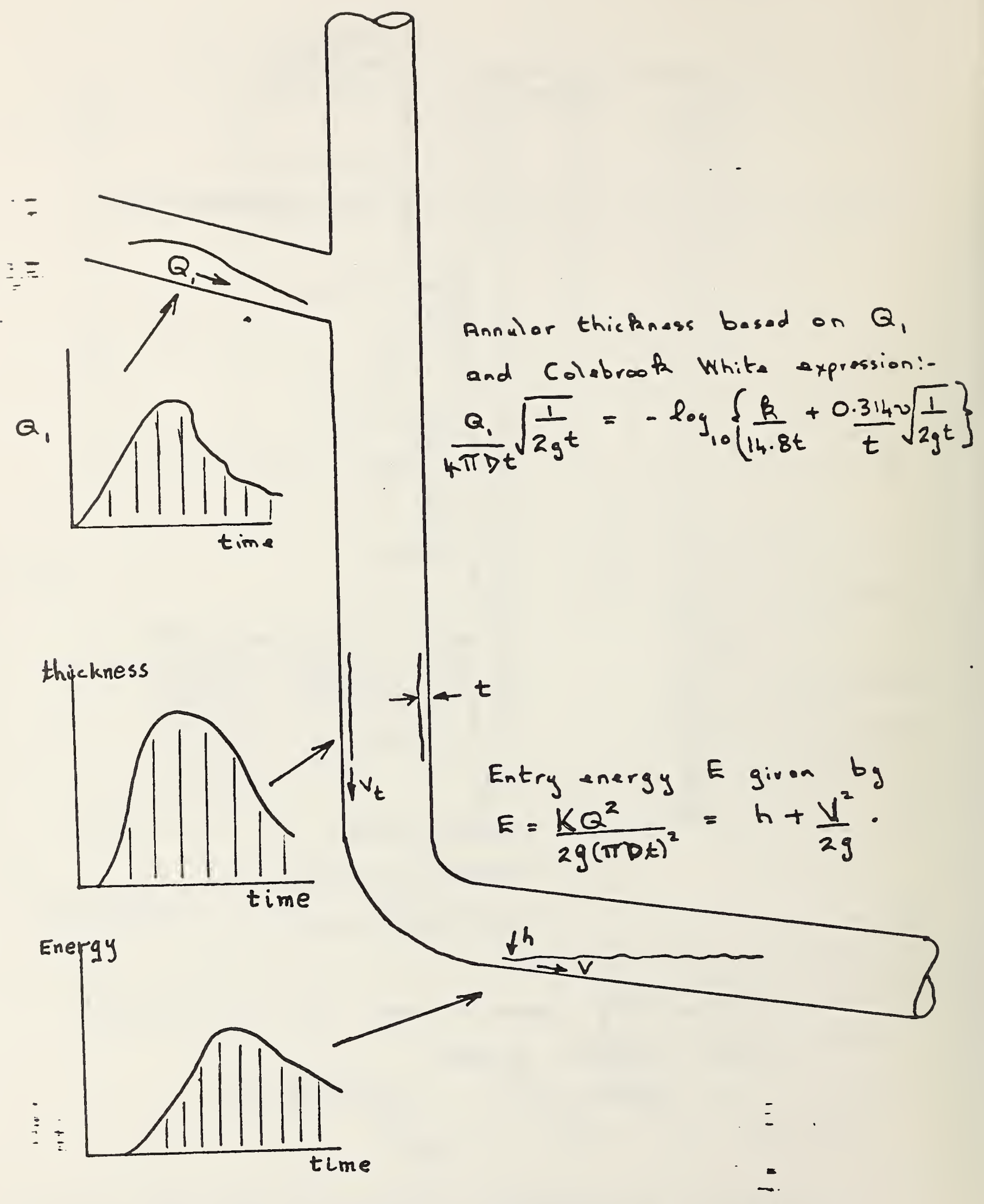

Figure 4. Flow rate vs. time inflow to a vertical stack translated into annular thickness and terminal energy vs. time profiles 

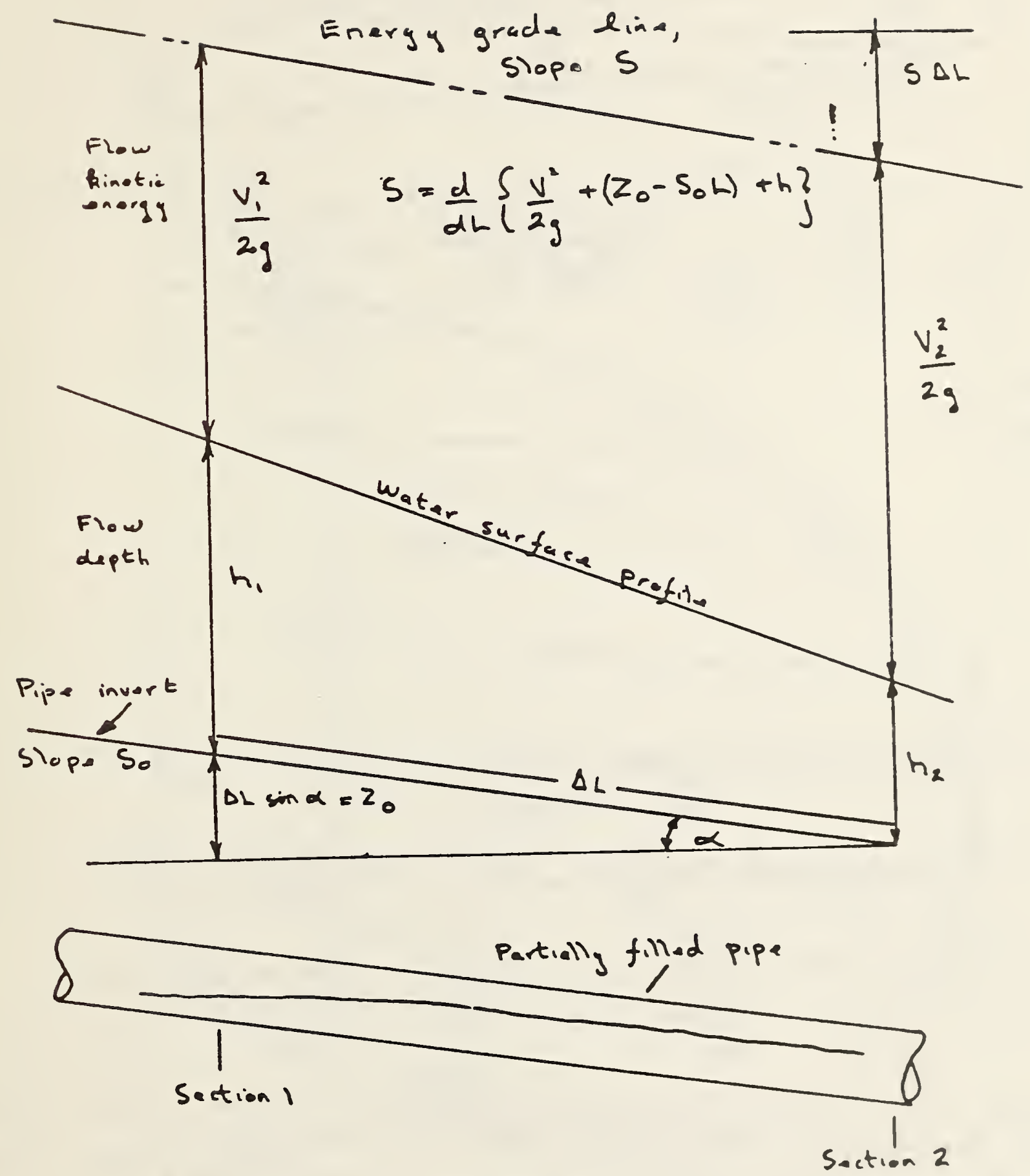

Gradually varied flow analysis based on head loss at any section being equal to the equivalent steady flow loss at that flow rate and other flow parameters

Figure 5. Calculation of the energy grade line for gradually varied flow 
Transition
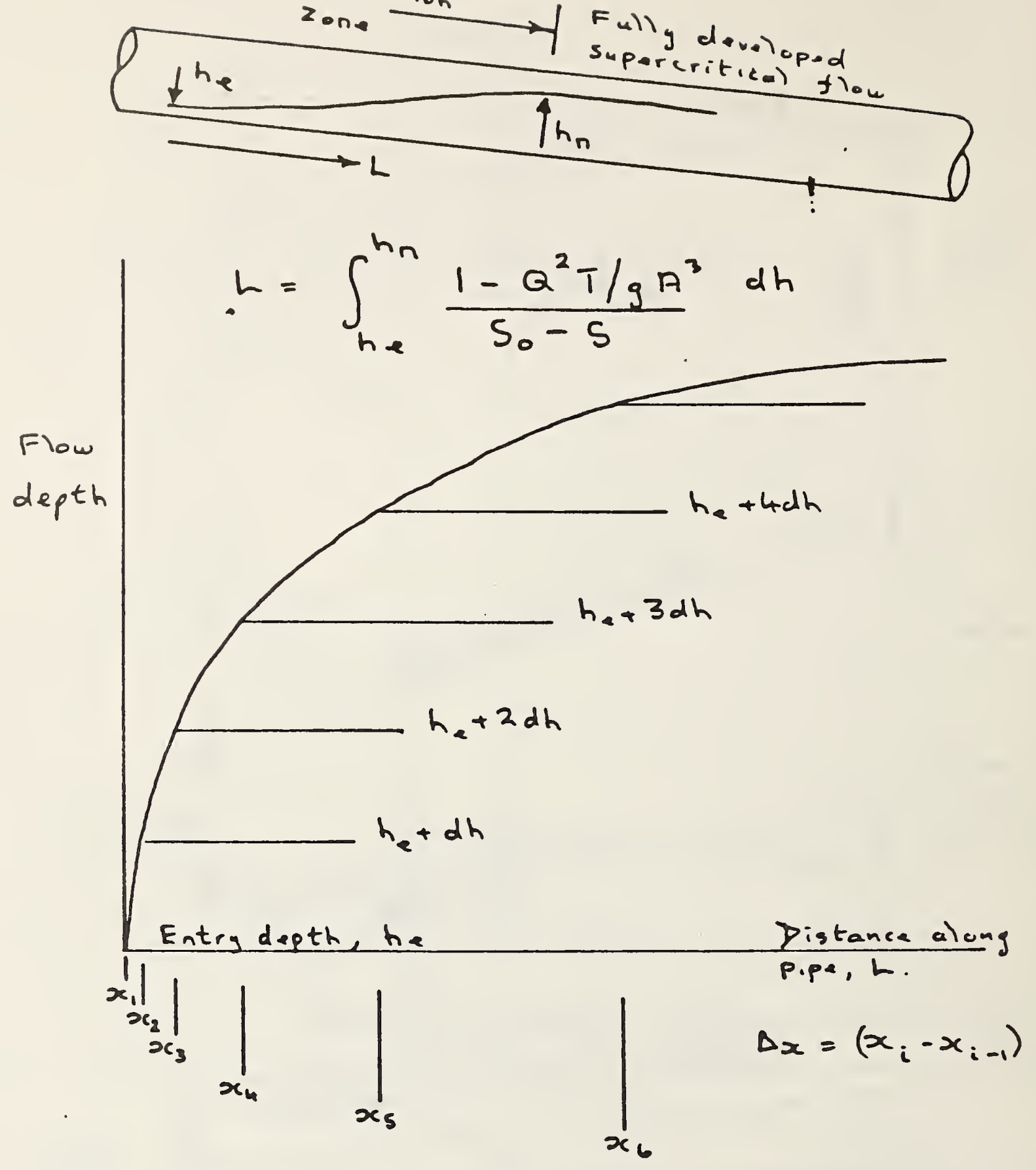

Note (1) As e increases as $L$ incuresas

(ii) flow depth approaches normal depth, $h_{n}$, smoothly only in supercritical flow (ii) A, $T$ both $f(h)$

(iv) $S$ calculated from Colebrock White

Figure 6. Development of flow depth profiles in gradually varied pip flow

20 


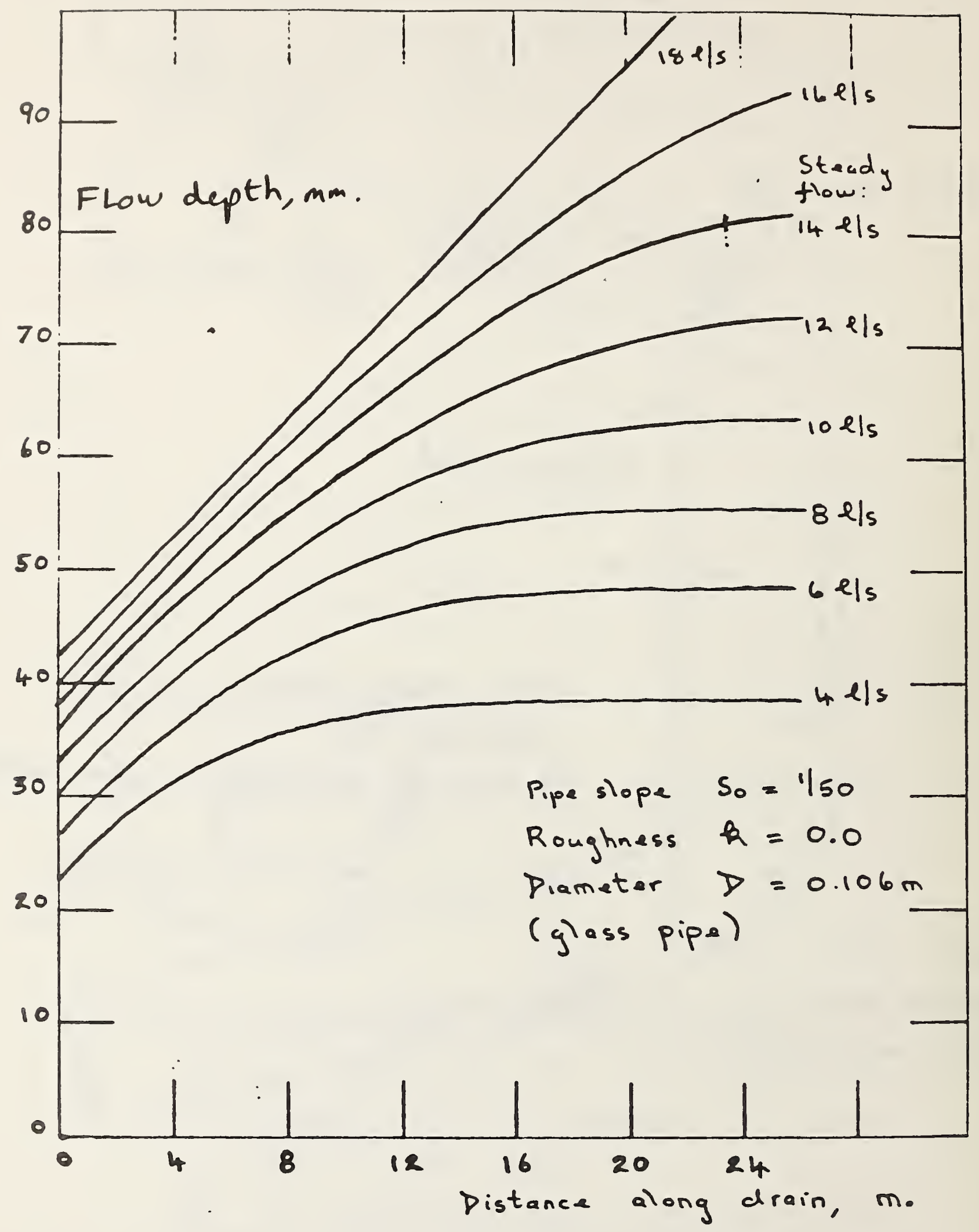

Figure 8. Depth profiles for an initial steady flow along the drain at a $1 / 50$ gradient, no energy loss at entry 


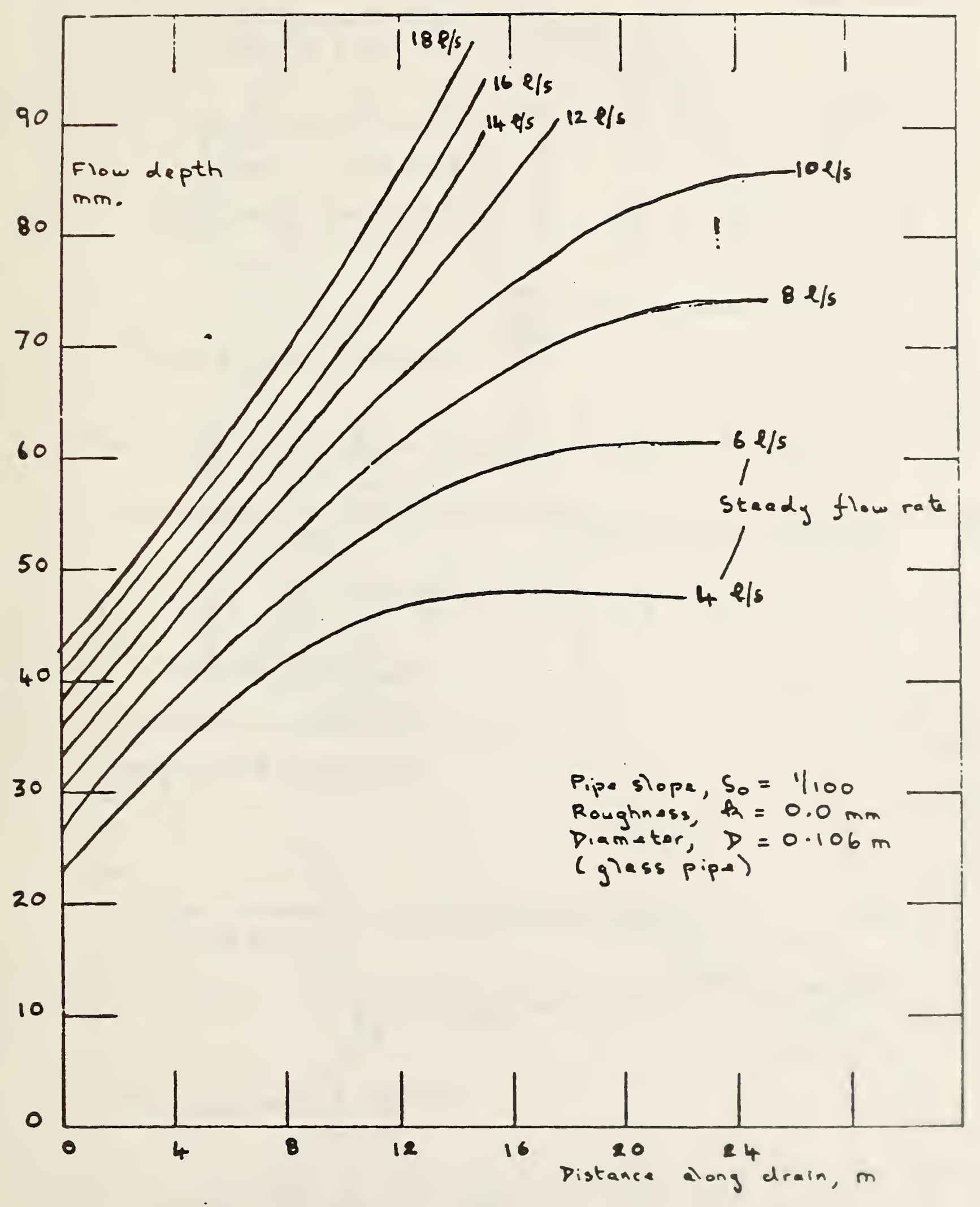

Figure 9. Depth profiles for an Initial steady flow along the drain at a $1 / 100$ gradient, no energy loss at entry 


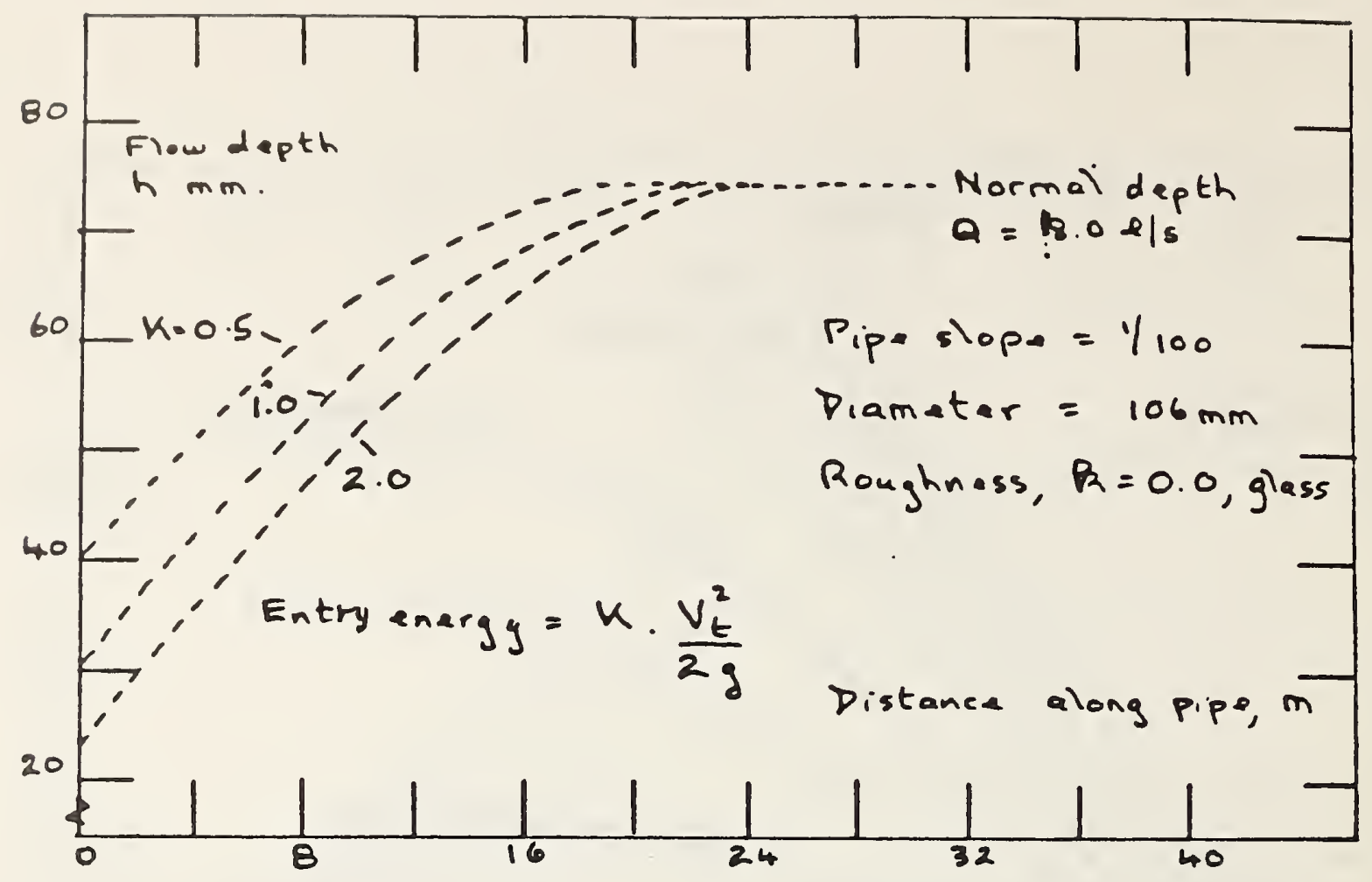

Figure 10. Influence of the entry energy loss coefficient on initial steady flow depth profiles $(1 / 100)$

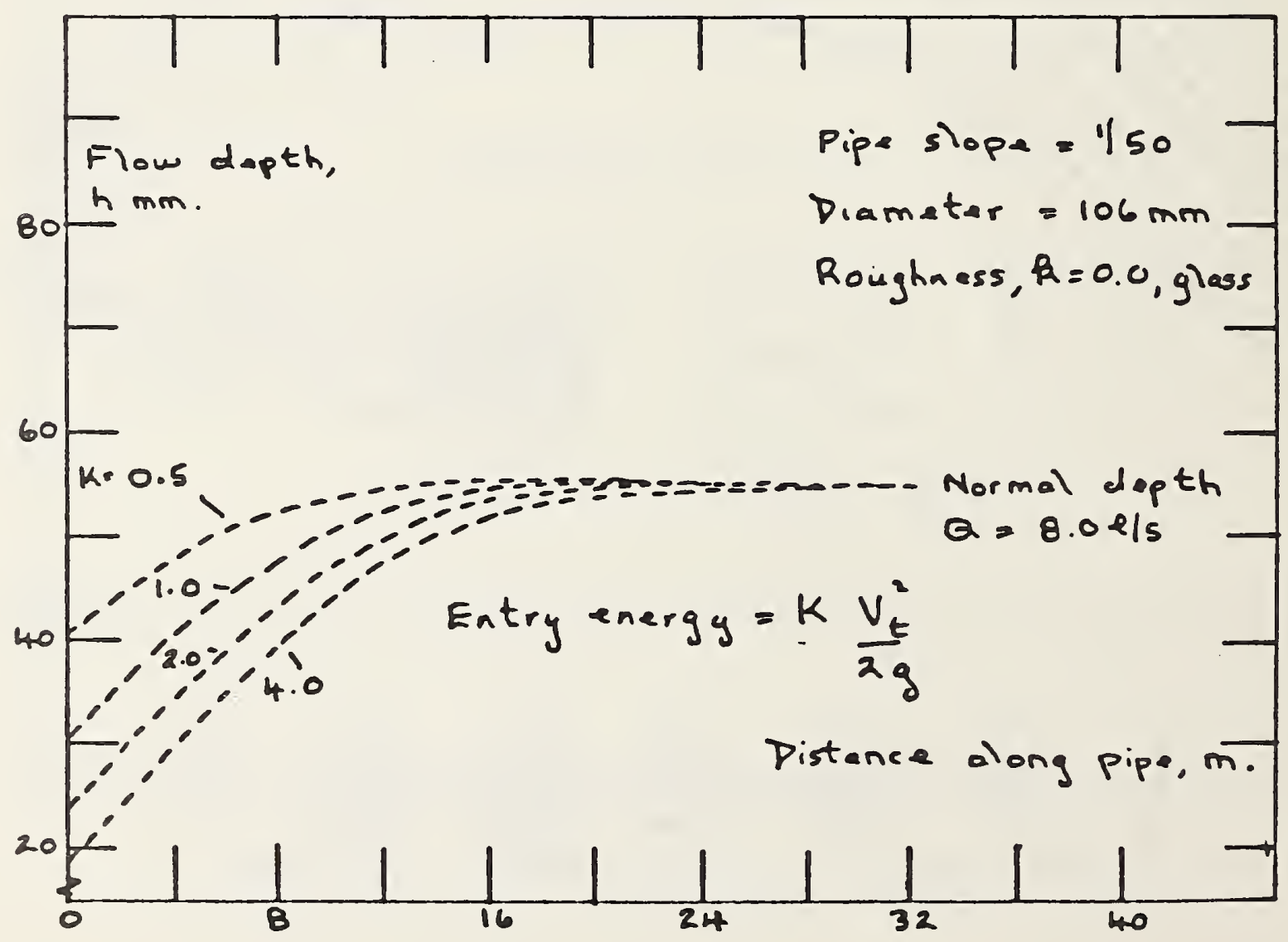

Figure 11. Influence of the entry energy loss coefficient on inftial steady flow depth profiles $(1 / 50)$ 


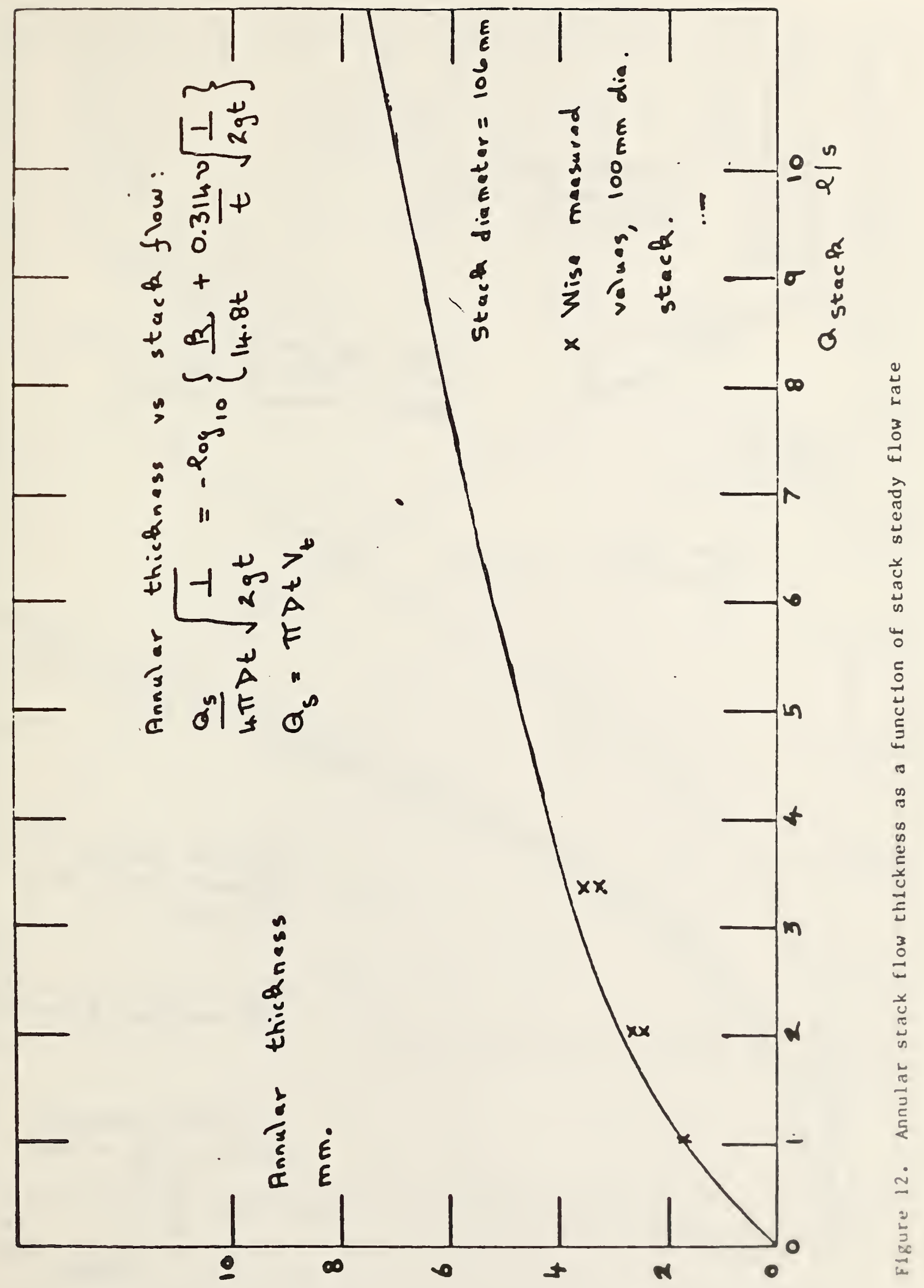




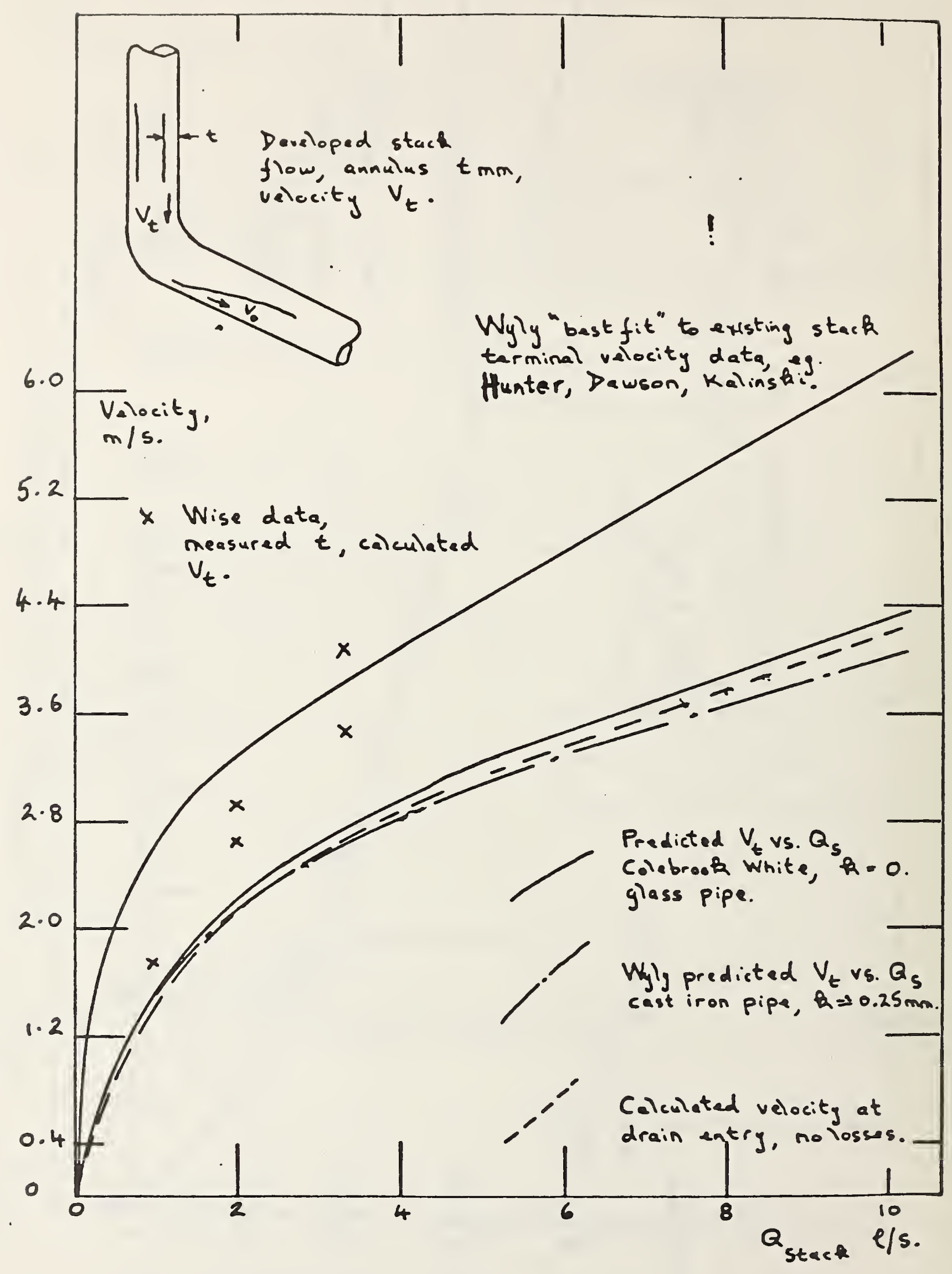

Figure 13. Stack annular flow terminal velocities compared to existing experimental data 


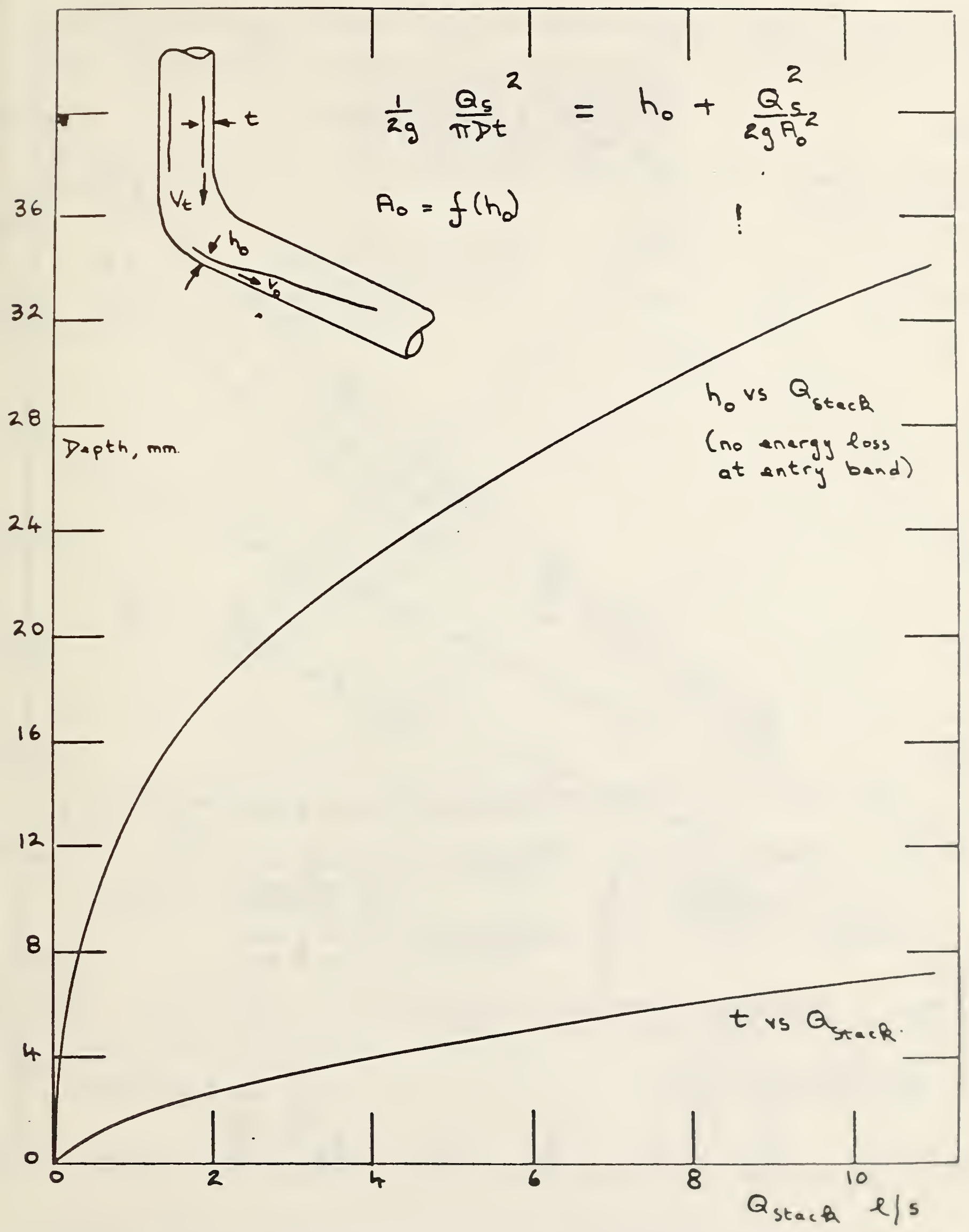

Figure 14. Flow depth at pipe entry compared to annular stack flow thickness for a range of steady flow rates 


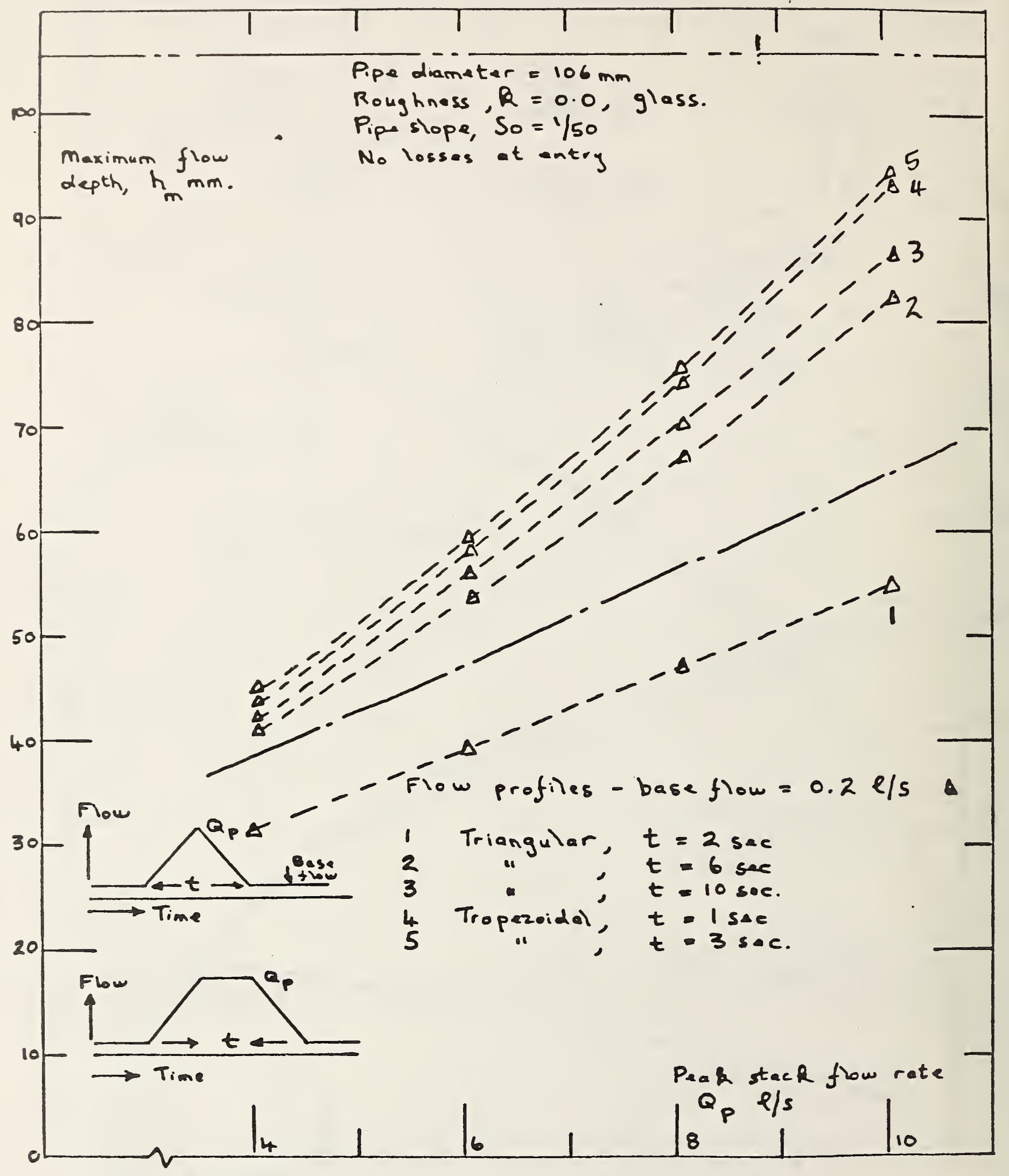

Figure 15. Peak depths predicted along the horizontal drain for a range of inflow profiles $(1 / 50)$

28 


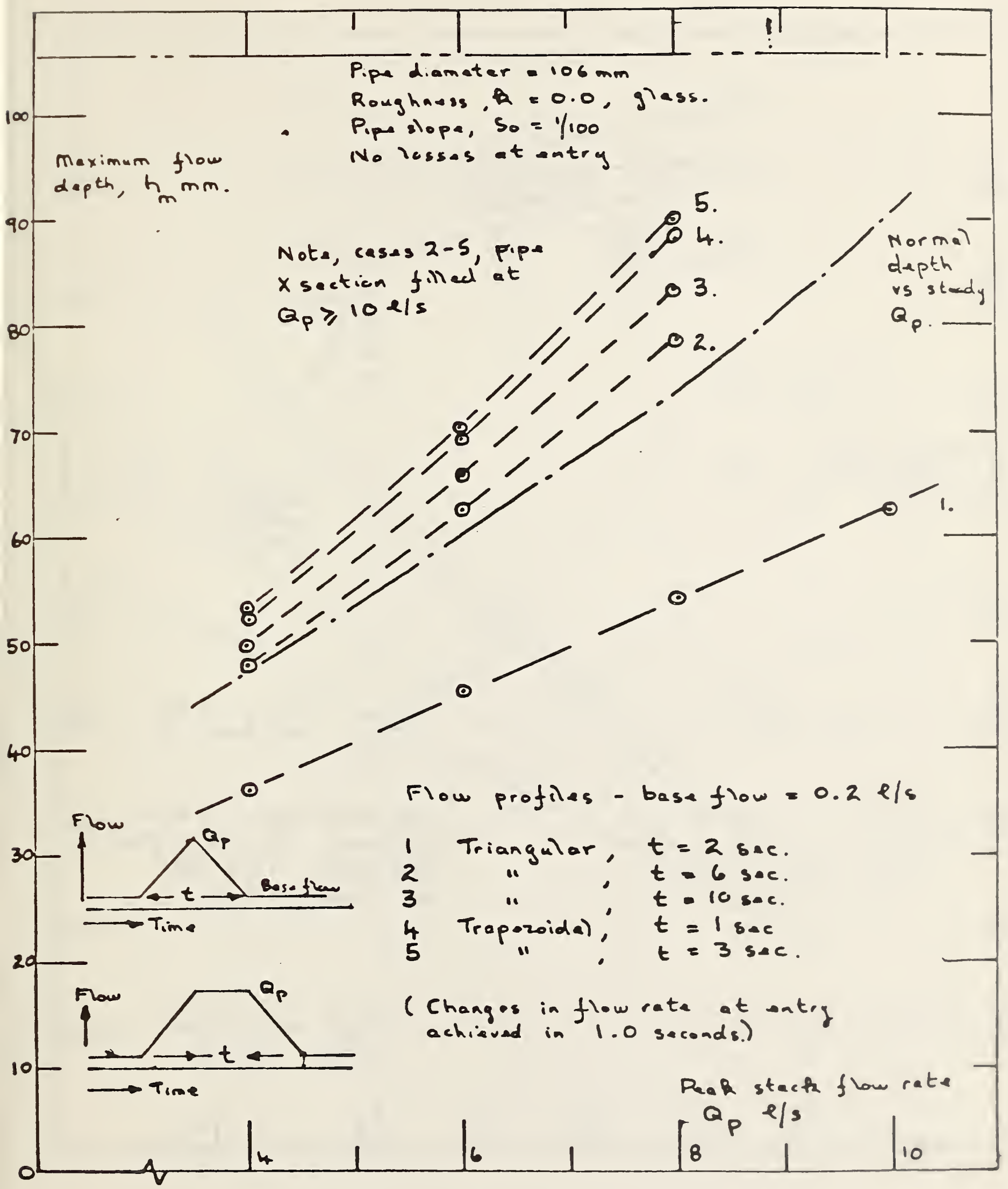

Figure 16. Peak depths predicted along the horlzontal drain for a range of inflow profiles $(1 / 100)$ 


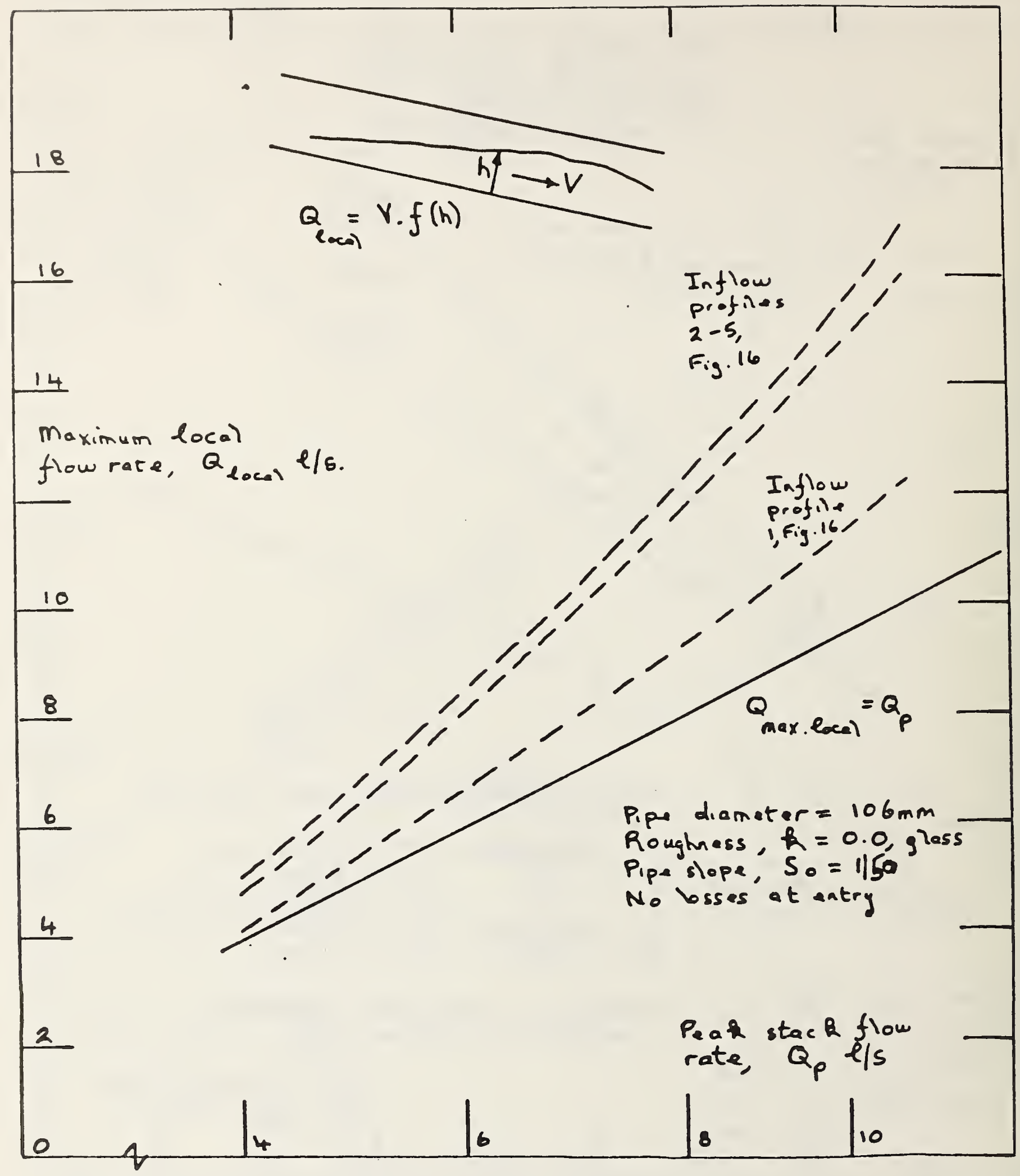

Figure 17. Peak Flow rates predicted locally along the horlzontal drain for a range of inflow profiles $(1 / 50)$ 


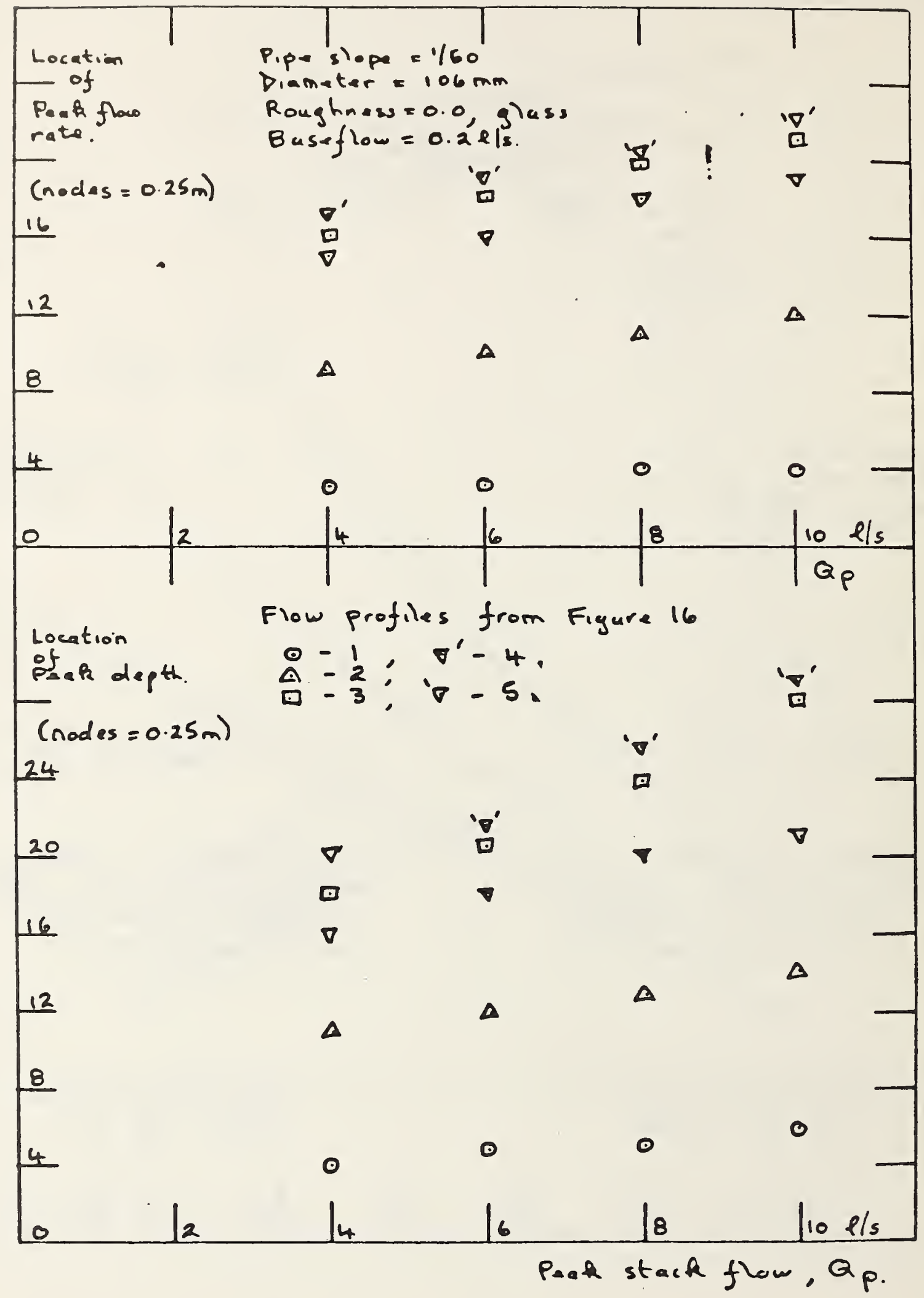

Figure 19. Location of predicted peak flow depth and local flow rate for a range of inflow profiles (1/50) 


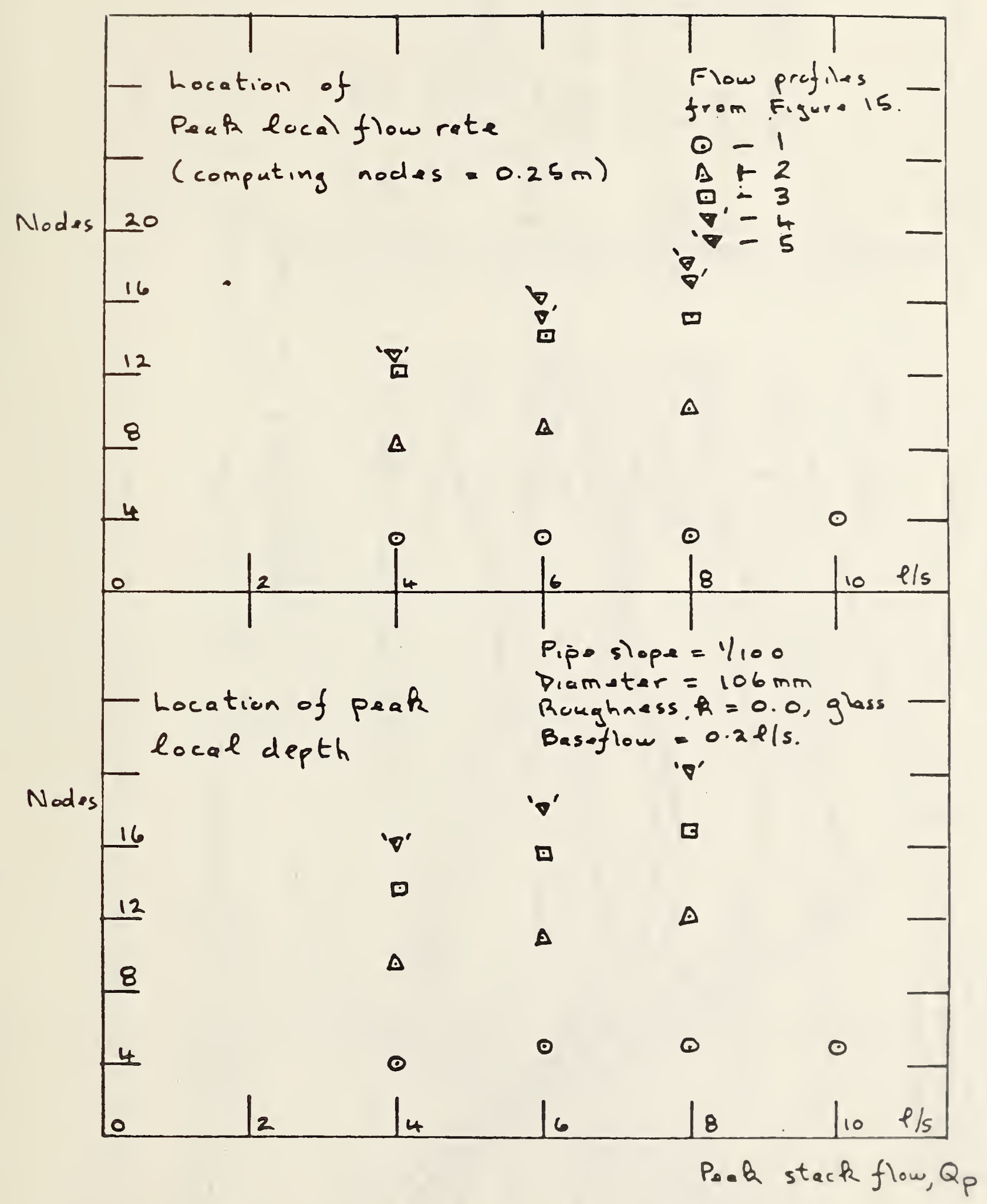

Figure 20. Location of predicted peak flow depth and local flow rate for a range of inflow profiles $(1 / 100)$ 


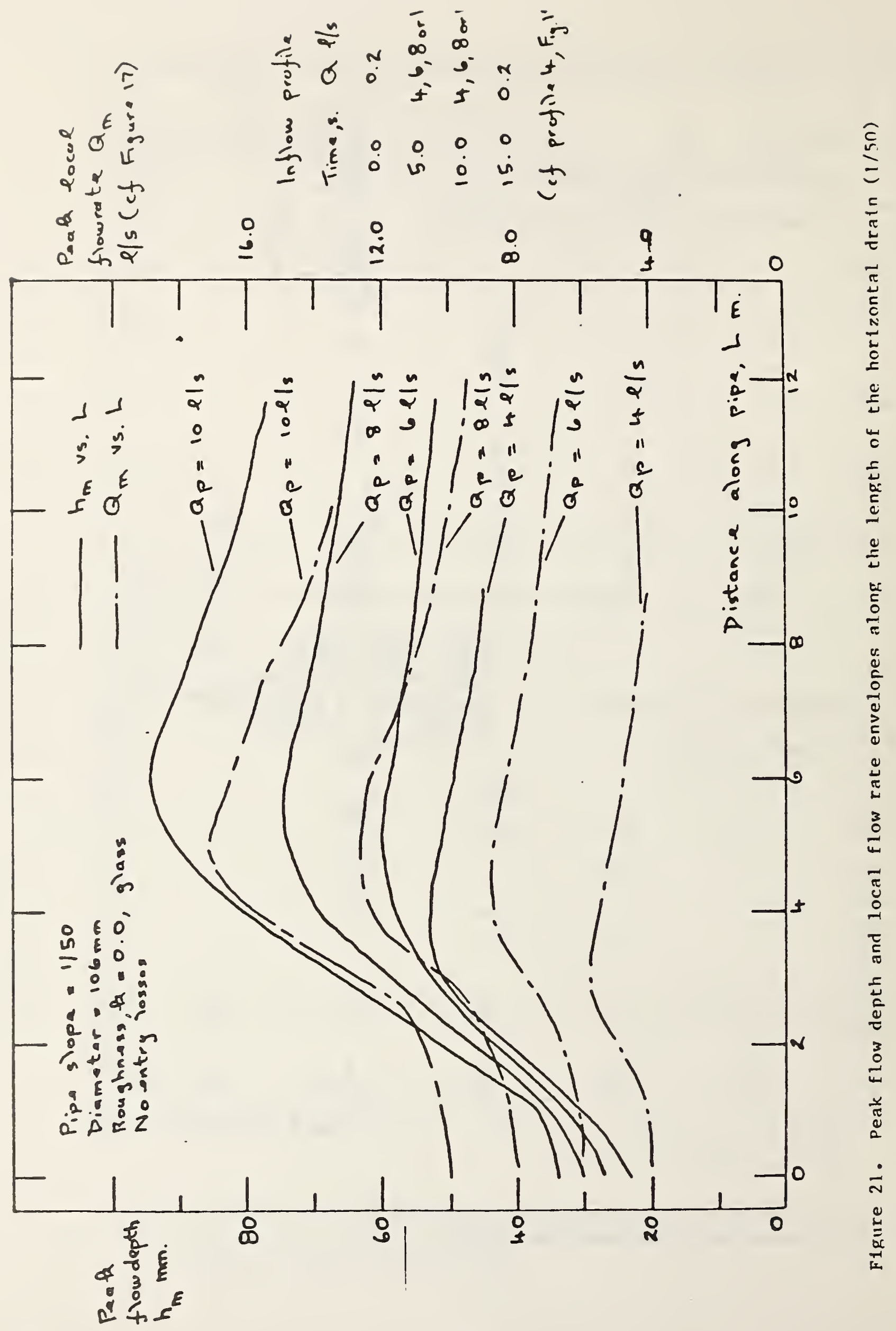




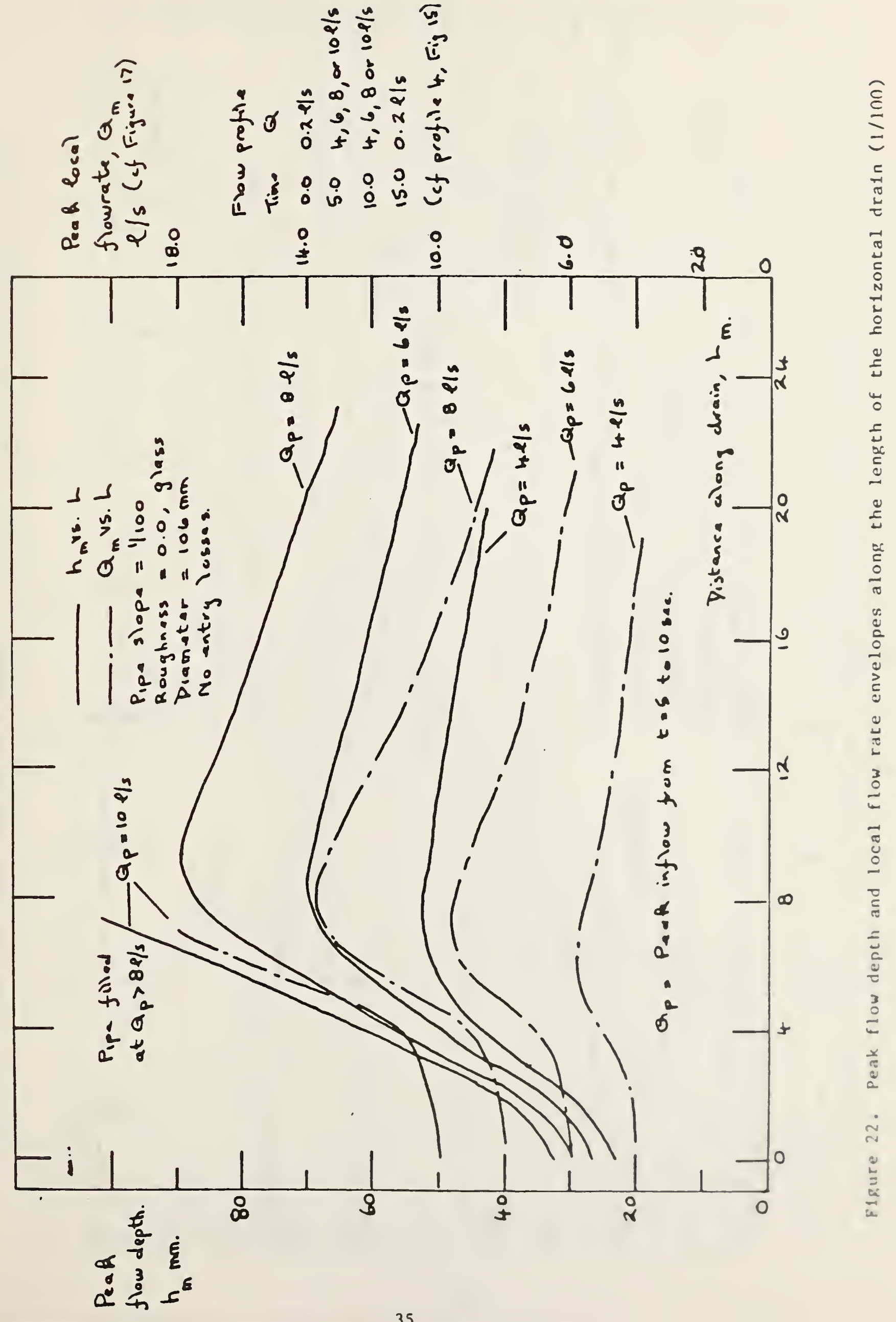




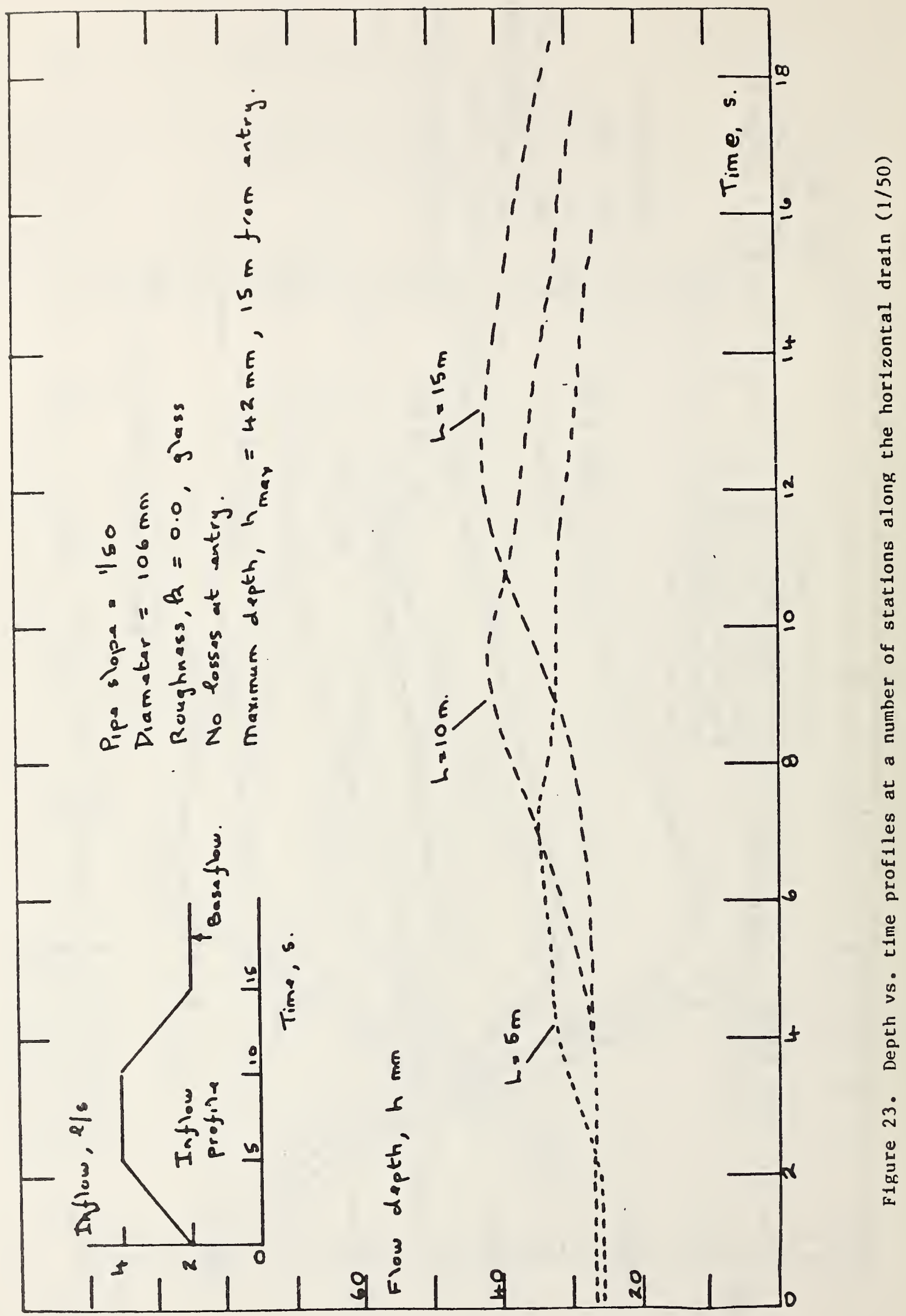




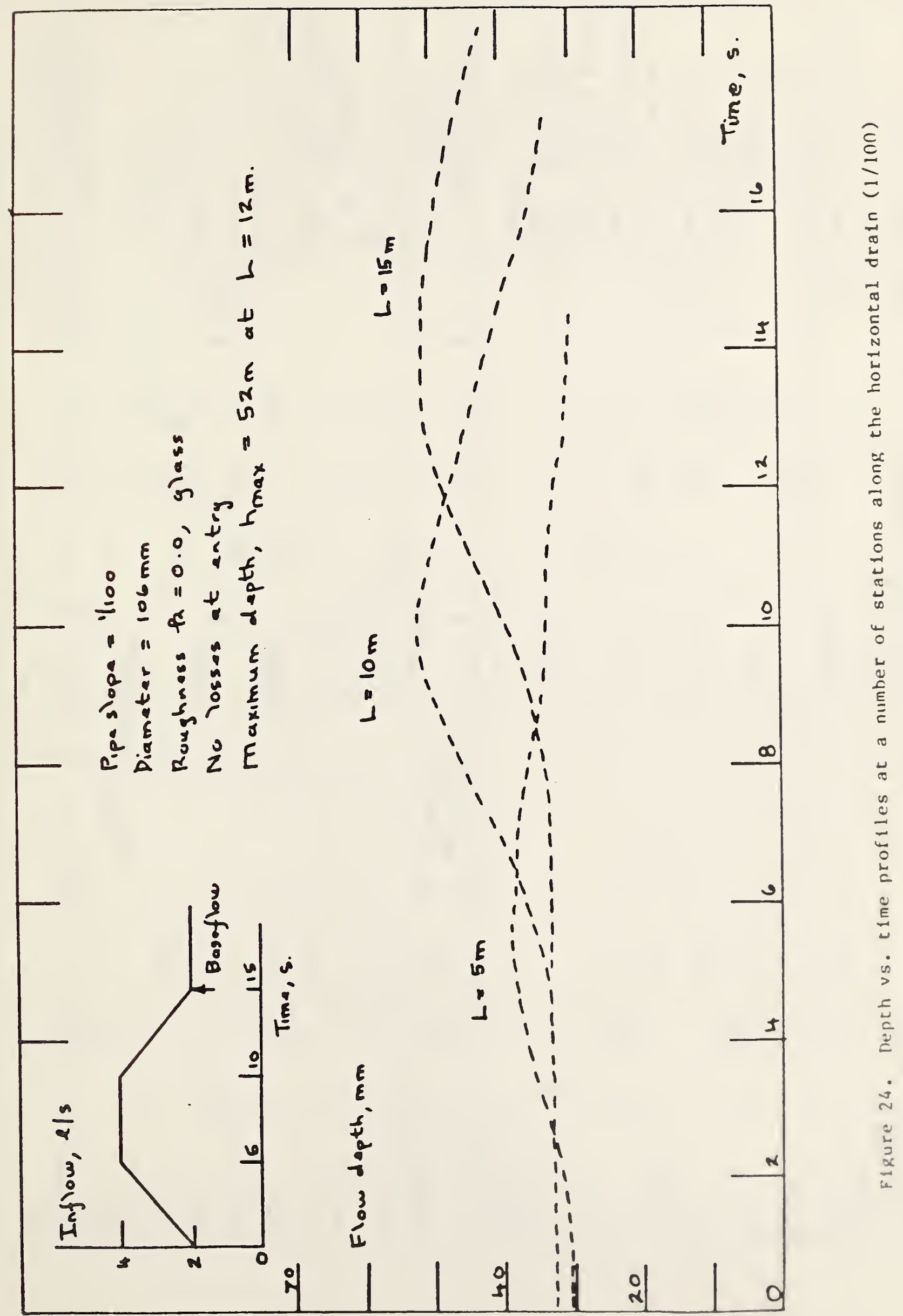




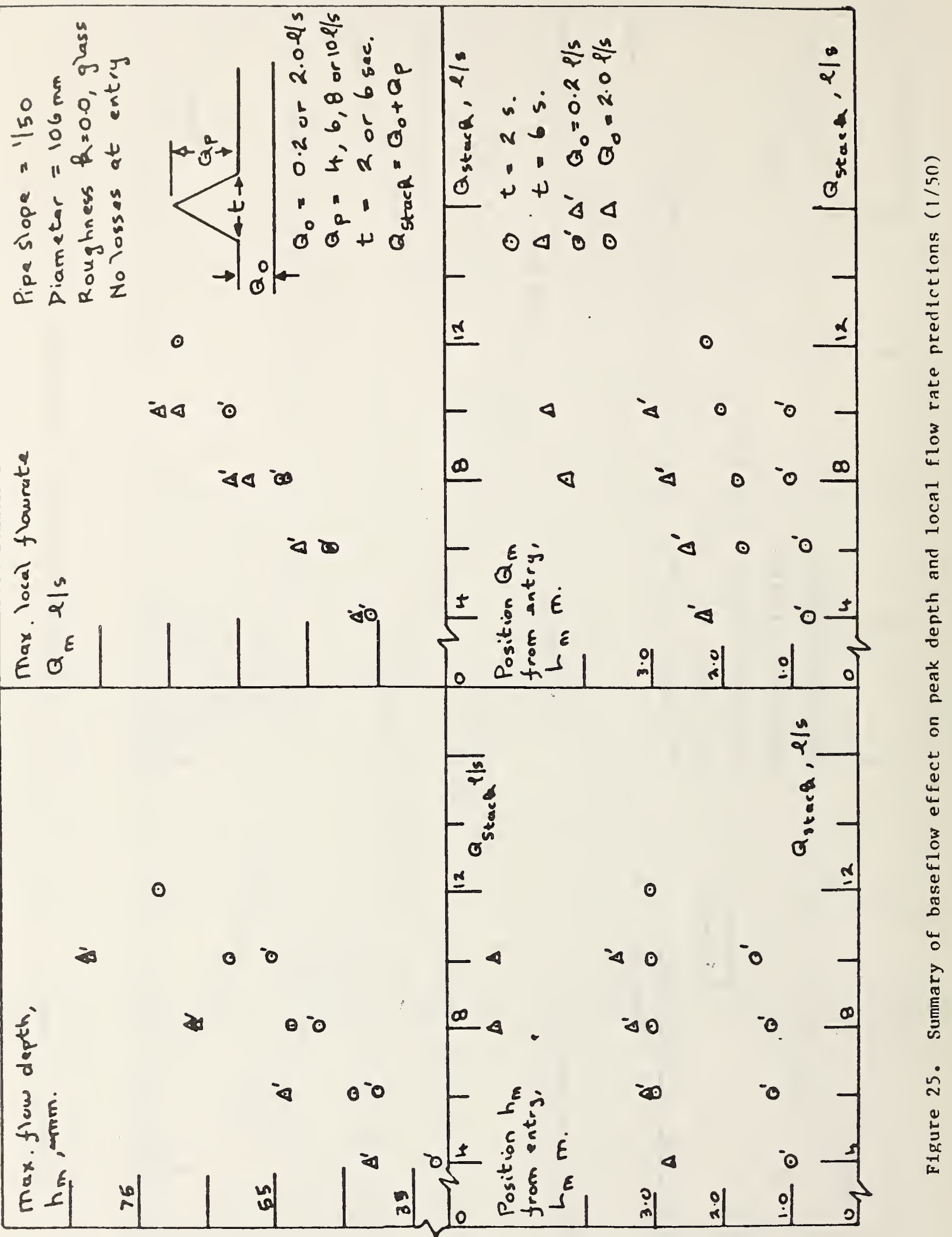




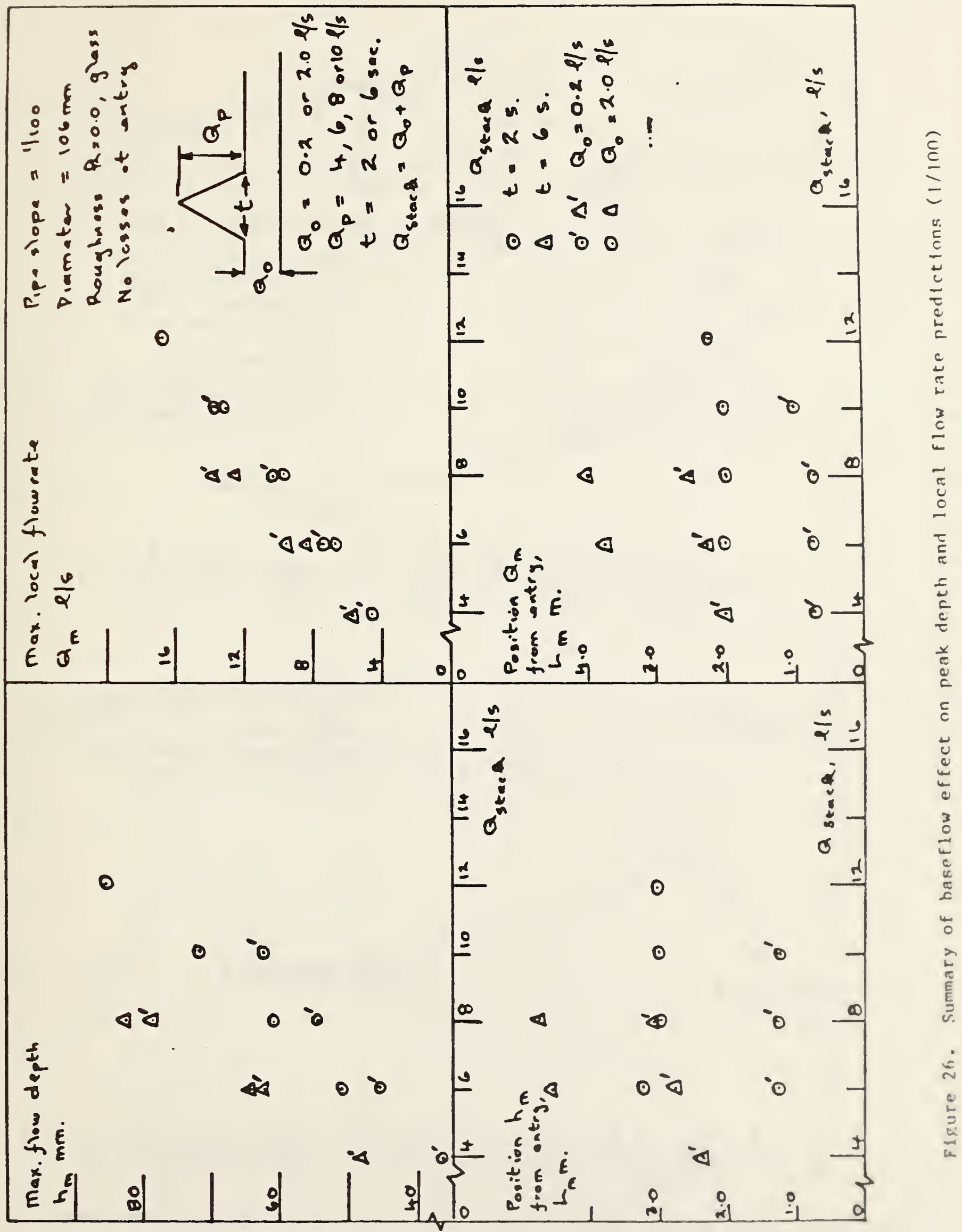



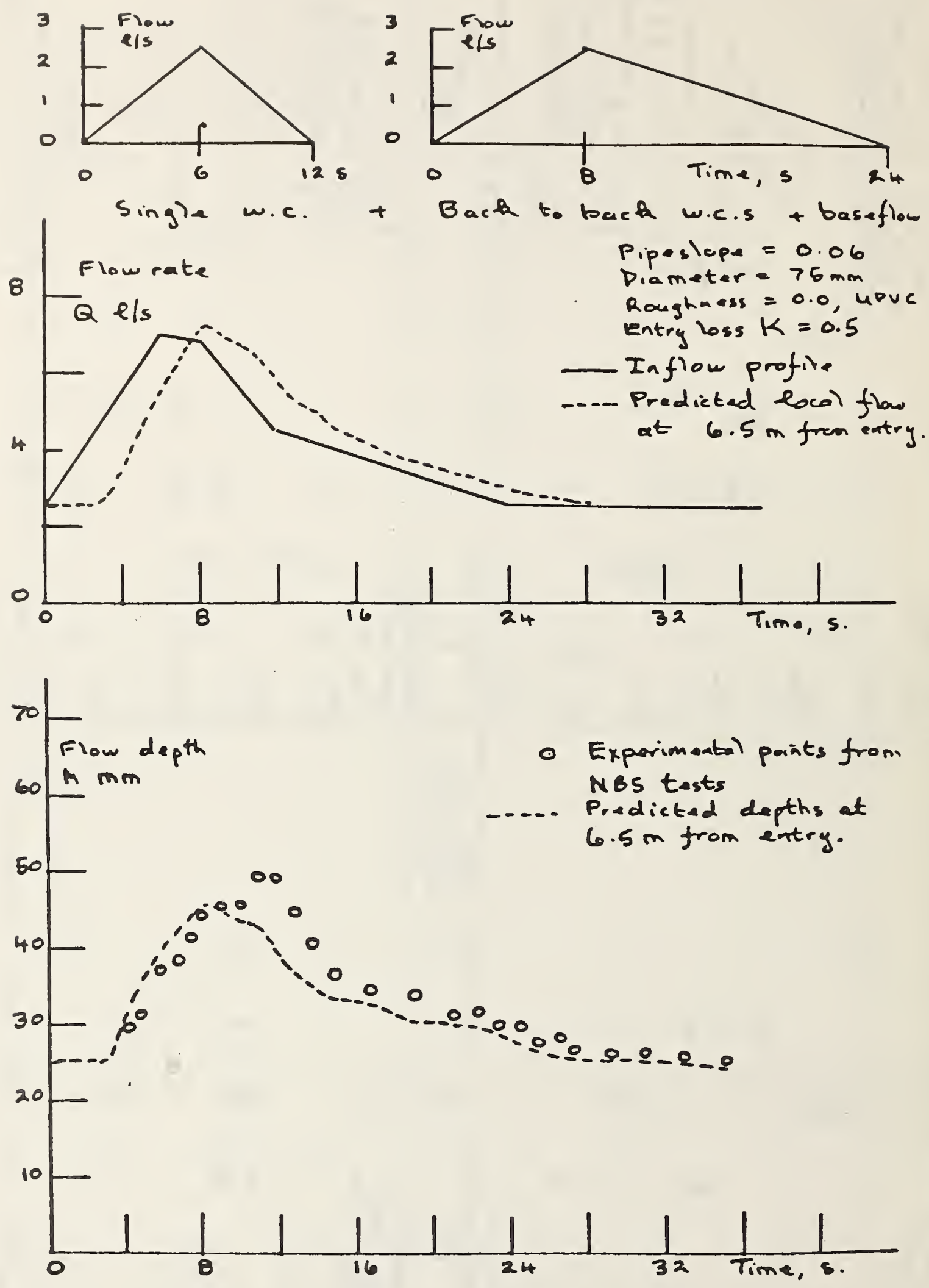

Figure 27. Comparison of observed and predicted surge attenuation downstream of a vertical stack to horizontal drain entry 

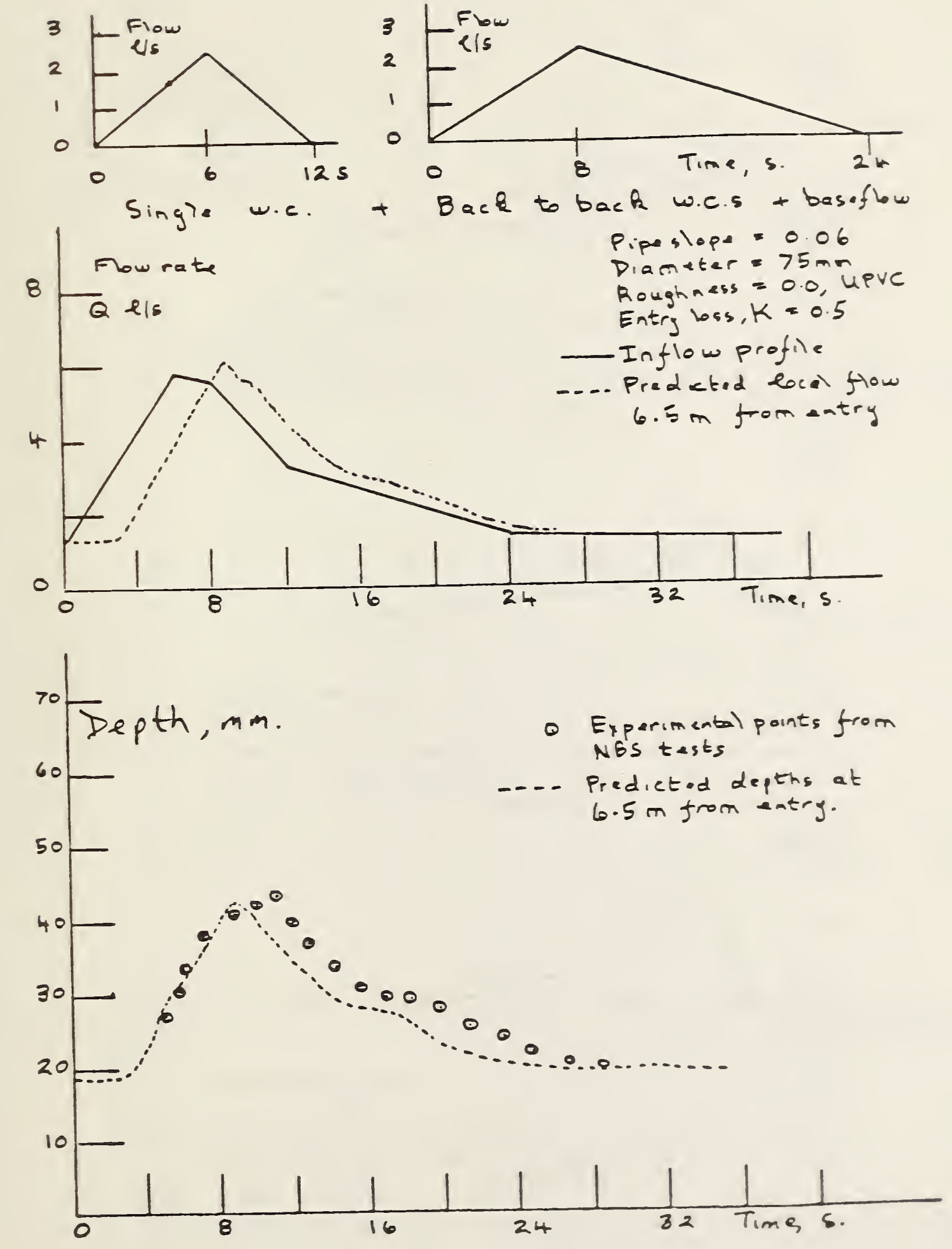

Figure 28. Comparison of observed and predicted surge attenuation downstream 

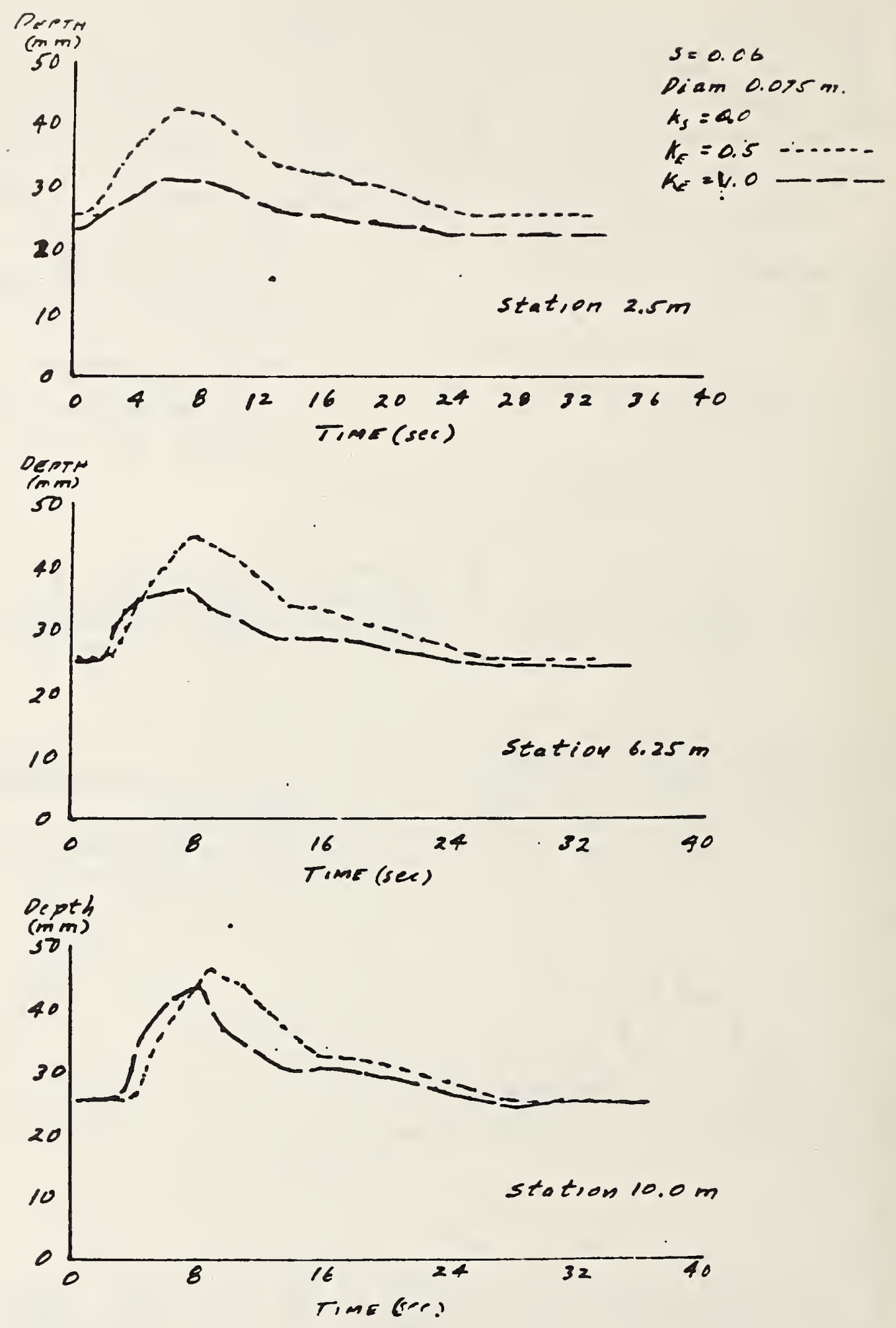

Figure 29. Comparison of predicted surge depths downstream of a vertical stack to a horizontal drain entry for two entry energy loss factors 

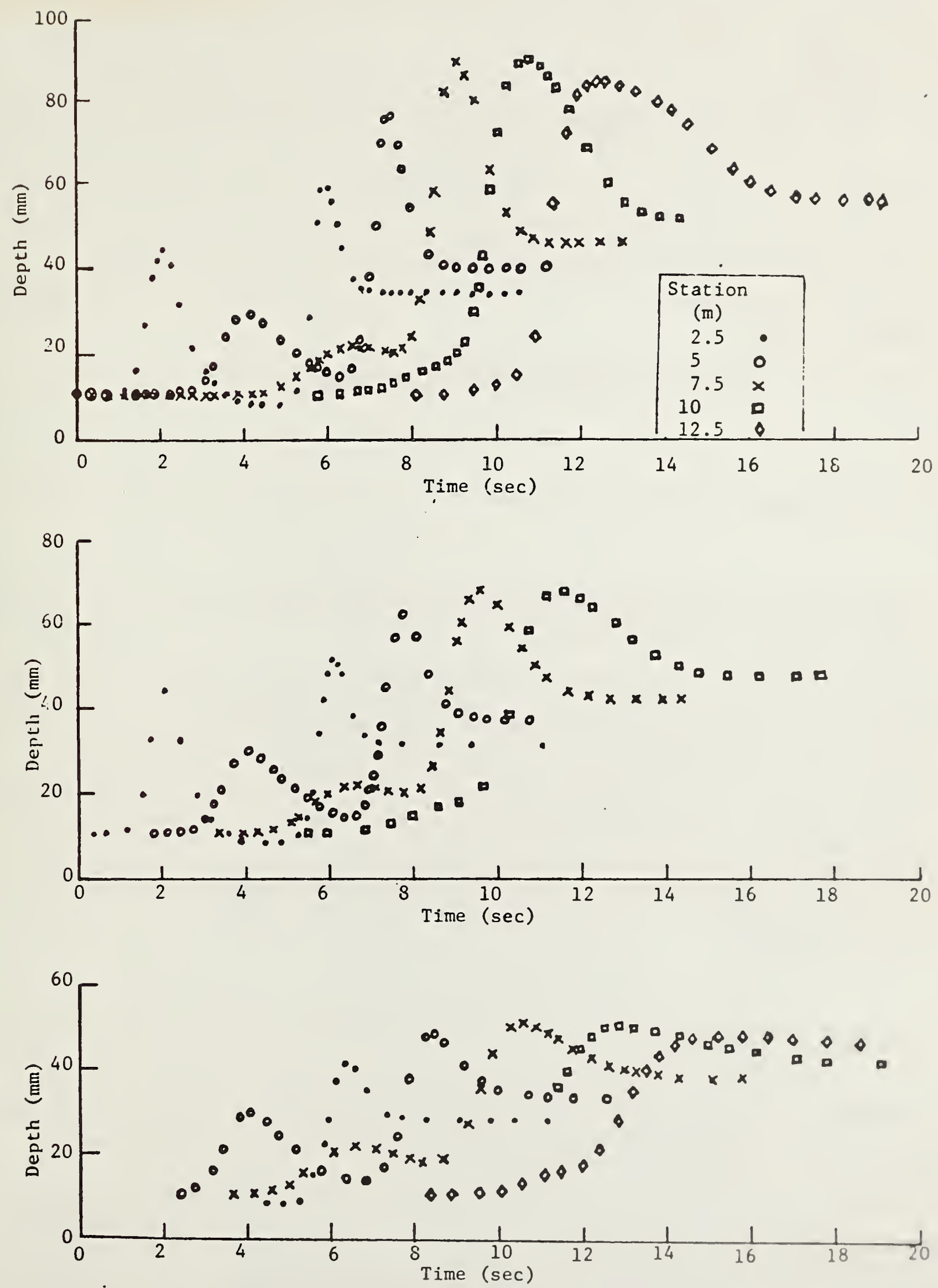

Figure 30. Comparison of predicted surge profile depths in a horlzontal drain downstrem of a vertical stack for composite loading profiles 
U.S. DEPT. OF COMM.

BIBLIOGRAPHIC DATA

SHEET (See instructions)
1. PUBLICATION OR
REPORT NO.
NBSIR $85-3108$
2. Performing Organ. Report No. 3. Publication Date

February 1985

4. TITLE AND SUBTITLE

A PRELIMINARY STUDY OF THE VERTICAL STACK TO HORIZONTAL DRAIN ENTRY CONDITION AS AN EXTENSION TO THE MODELING OF UNSTEADY PARTIALLY FILLED PIPE FLOW

5. AUTHOR(S)

Dr. J. A. Swaffield, Lawrence S. Galowin

6. PERFORMING ORGANIZATION (If joint or other than NBS, see instructions)

7. Contract Grant No.

NATIONAL BUREAU OF STANDARDS

DEPARTMENT OF COMMERCE

8. Type of Report \& Period Covered

WASHINGTON, D.C. 20234

9. SPONSORING ORGANIZATION NAME AND COMPLETE ADDRESS (Street, City, Stote, ZIP)

10. SUPPLEMENTARY NOTES

[Document describes a computer program; SF-185, FIPS Software Summary, is attached.

11. ABSTRACT (A 200-word or less factual summary of most significant information. If document includes a significant bibliography or literature survey, mention it here)

The finite difference based method of characteristics model for unsteady partially filled pipe flow was extended to include the stack to horizontal drain entry boundary condition. The conditions at drain entry are defined in terms of the energy of the terminal annular flow velocity in the stack, together with an appropriate loss coefficient as the entry function. The hydraulic solutions link the branch drains, fittings, vertical soil stack and building drain. The analysis permits any combination of drainage load patterns from simultaneous, overlapping or sequence of discharge events. Preliminary simulations utilizing this model indicates that the modeling technique extends the existing horizontal network analysis program to a simulation of multistory building drainage systems. The sizing procedure determines the hydraulic capacity of drains for specified pipe sizes, pipe pitch and well roughness factors.

12. KEY WORDS (Six to twelve entries; alphabetical order; capitalize only proper names; and separate key words by semicolons) drain stack to horizontal drain flows; drain system design; plumbing drainage; unsteady flow in drainage

13. AVAILABILITY

[X] Unlimited

For Official Distribution. Do Not Release to NTIS

Order From Superintendent of Documents, U.S. Government Printing Office, Washington, D.C. 20402.

[X] Order From National Technical Information Service (NTIS), Springfield, VA. 2216I
14. NO. OF PRINTED PAGES

\section{3}

15. Price 

